NBER WORKING PAPER SERIES

\title{
PASS-THROUGH AS A TEST FOR MARKET POWER: AN APPLICATION TO SOLAR SUBSIDIES
}

\author{
Jacquelyn Pless \\ Arthur A. van Benthem \\ Working Paper 23260 \\ http://www.nber.org/papers/w23260 \\ NATIONAL BUREAU OF ECONOMIC RESEARCH \\ 1050 Massachusetts Avenue \\ Cambridge, MA 02138 \\ March 2017, Revised November 2018
}

A prior version of this paper was circulated under the title "The Surprising Pass-Through of Solar Subsidies." We thank Edward Balistreri, Chrystie Burr, Harrison Fell, Ken Gillingham, Cameron Hepburn, Jean-François Houde, Jonathan Hughes, Koichiro Ito, Daniel Kafine, Ian Lange, Peter Maniloff, Alex Teytelboym, Tsvetan Tsvetanov, Eugene Vorobeychik and seminar participants at the 2016 AERE Summer Conference, 2017 National Tax Association Conference, 2017 NortheastWorkshop on Energy Policy and Environmental Economics, 2018 AEA/ASSA Conference, 2018 Royal Economic Society Conference, Colorado School of Mines, Harvard University, UC Berkeley, University of Cambridge, University of Colorado Boulder, University of Manchester, University of Oxford, and the University of Pennsylvania for helpful comments and suggestions. We especially thank Ruben Lobel for comments during the early stage of this research. We thank the National Renewable Energy Laboratory (NREL) and the Center for Sustainable Energy for helpful institutional insights. Pless thanks the Oxford Martin Programme on Integrating Renewable Energy at the Oxford Martin School, University of Oxford. Van Benthem thanks the Wharton Dean's Research Fund.

NBER working papers are circulated for discussion and comment purposes. They have not been peer-reviewed or been subject to the review by the NBER Board of Directors that accompanies official NBER publications.

(C) 2017 by Jacquelyn Pless and Arthur A. van Benthem. All rights reserved. Short sections of text, not to exceed two paragraphs, may be quoted without explicit permission provided that full credit, including $\odot$ notice, is given to the source. 
Pass-Through as a Test for Market Power: An Application to Solar Subsidies

Jacquelyn Pless and Arthur A. van Benthem

NBER Working Paper No. 23260

March 2017, Revised November 2018

JEL No. H22,Q42,Q48,Q58

\section{ABSTRACT}

We formalize pass-through over-shifting as a simple yet under-utilized test for market power. We apply this test in the market for solar energy. Specifically, we estimate the pass-through of solar subsidies to solar system prices using rich micro-level transaction and subsidy data from California. Buyers of solar systems capture nearly the full subsidy, while there is more-thancomplete pass-through to lessees. We conclude that solar markets are imperfectly competitive by ruling out alternative explanations for over-shifting, and reinforce this conclusion with a test of solar demand curvature. This procedure can serve to detect market power beyond the solar market.

Jacquelyn Pless

University of Oxford

Eagle House, Walton Well Road

Oxford OX2 6ED

United Kingdom

jacquelyn.pless@ouce.ox.ac.uk

Arthur A. van Benthem

The Wharton School

University of Pennsylvania

1354 Steinberg Hall - Dietrich Hall

3620 Locust Walk

Philadelphia, PA 19104

and NBER

arthurv@wharton.upenn.edu 


\section{Introduction}

Pass-through of taxes and subsidies - or more generally, cost shocks - to prices plays an important role in economic analysis and policy evaluation across numerous fields of economics. In public economics, pass-through holds a prominent position in the theory of tax incidence and distributional equity (Busse et al. 2006; Marion and Muehlegger 2011; Sallee 2011; Weyl and Fabinger 2013; Ito 2015; Ganapati et al. 2016; Kopczuk et al. 2016). The topic has also attracted considerable attention in industrial organization, particularly because pass-through can elucidate the welfare implications from various types of price discrimination or imperfect competition (Fabra and Reguant 2014).

Under certain conditions, there is a direct connection between pass-through and the existence of market power. While theory predicts - and empirical studies confirm - that pass-through rates fall between 0 and 100 percent across a wide range of market structures, those above 100 percent cannot be ruled out theoretically. Such "over-shifting" is not just an economic curiosity. In fact, it is often observed (Besley and Rosen 1999; Delipalla and O'Donnell 2001; Kenkel 2005). More importantly, it can reveal important characteristics about supply, demand, or market power, as theory only rationalizes it under a narrow set of assumptions. For example, the theory of incidence tells us that markets characterized by various forms of imperfect competition exhibit over-shifting if demand is very convex (Seade 1985; Weyl and Fabinger 2013).

In this paper, we formalize under what conditions over-shifting can be used as a simple and direct test for market power and demonstrate how estimating demand convexity can corroborate such a conclusion. In doing so, we strengthen the connection between theory and data which has remained loose in existing empirical papers that find over-shifting and discuss the presence of market power as a way to explain their findings. ${ }^{1}$ We provide alternative explanations for overshifting that do not rely on imperfect competition and argue that they are unlikely to be relevant in many markets. Thus, when judiciously applied, a finding of over-shifting from a straightforward pass-through estimation can serve as evidence of market power, without the need for a structural model of the market in question.

We study these issues in an important empirical setting that, perhaps surprisingly, exhibits pass-through over-shifting: the market for residential solar systems in California, where about half of all U.S. residential solar systems are located (Borenstein 2017). ${ }^{2}$ The availability of transactionlevel microdata makes solar markets well-suited for econometric estimation of subsidy pass-through. Furthermore, beyond its exposition of over-shifting, this market is especially interesting and important in its own right. Governments around the world spent $\$ 120$ billion subsidizing renewables

\footnotetext{
${ }^{1}$ Ritz (2015) points out that the empirical literature has rarely tested whether standard theory can explain specific pass-through patterns. The context discussed is asymmetric pass-through, but the same observation applies for overshifting and other "surprising" patterns of pass-through.

${ }^{2}$ Governments use these subsidies to (indirectly) address environmental externalities by increasing renewable energy uptake. Another motivation is to correct for non-appropriable learning-by-doing spillovers in solar installation technology (van Benthem et al. 2008; Bollinger and Gillingham 2014). While the impact of solar subsidies on solar system adoptions has been studied (Burr 2014; Hughes and Podolefsky 2015), much less is known about their passthrough to consumers, which is a crucial input in the calculation of who ultimately benefits from the subsidies (i.e., the economic incidence).
} 
in 2014 and $\$ 50$ billion on solar alone (International Energy Agency 2016). In the United States, it is not unusual for federal- and state-level incentives to add up to half the total system costs (Gillingham and Tsvetanov 2017).

There are several other unique characteristics that make the solar market particularly interesting from an economist's perspective. First, solar adopters use different system ownership structuresnamely, host-ownership (HO) versus third-party ownership (TPO) - analogous to buying versus leasing in other markets such as the automobile market. We can therefore estimate how passthrough differs between owners and lessees of the same product. Such comparisons are rare in the literature. Second, the incidence of renewable energy subsidies has been a topic of intense debate and there are direct concerns about low pass-through in the TPO solar market. ${ }^{3}$ Consumer advocacy groups have accused solar companies of deceptive sales tactics (Greentech Media 2016) and "scamming" homeowners out of their tax credits instead of transferring them to consumers (Watchdog Wire 2014). Lastly, and central to the focus of this paper, there have been worries about market power in solar markets (Gillingham et al. 2016; Nemet et al. 2017; Pless et al. 2017). In fact, the U.S. Federal Trade Commission held a workshop in 2016 to examine a variety of solar market competition issues (Kalpin et al. 2016). Market power concerns are particularly pertinent in the TPO context as a number of mergers between financing and installation companies have taken place. These vertically integrated firms include some of the industry's biggest players like SolarCity and Vivint who controlled 34 percent of the market in 2013 (McIntosh and Mandel 2014). ${ }^{4}$

We therefore estimate pass-through for both HO and TPO systems, test if they differ and exceed 100 percent, and if so, if we can take this as evidence that the solar market is imperfectly competitive. To further connect our empirical results with theory, we estimate demand curves in a sufficiently flexible form that allows us to test if our over-shifting finding is consistent with our estimated curvature of demand.

Specifically, we study the multi-billion dollar California Solar Initiative (CSI) program, the largest state rebate program for solar so far in the United States, which provides lump-sum upfront payments for solar system installations. An attractive econometric feature of the program is that it involved sharp drops in rebate levels across time and space. We collect solar system-level data on rebates received and system characteristics. However, while public data include transaction prices for HO systems, the prices for TPO systems are known to be inconsistently reported, making any analysis of TPO systems using CSI data "fundamentally flawed" (Greentech Media 2013). A novel feature of our analysis is that we construct (post-incentive) prices for TPO systems by calculating the (subsidy-inclusive) net present cost based upon actual contract terms - such as monthly lease

\footnotetext{
${ }^{3}$ A separate incidence concern relates to regressivity. Borenstein and Davis (2016) show that most clean energy tax incentives, including solar subsidies, are highly regressive: the top income quintile has received about 60 percent of all government support.

${ }^{4}$ Green subsidies have also been criticized for having mixed environmental success due to infra-marginal uptake. They suffer from an additionality problem as some green behavior would occur even in absence of the subsidies. Boomhower and Davis (2014) study how this problem affects the cost-effectiveness of an energy-efficient appliance subsidy program in Mexico and find that about half of the participants would have adopted the technology with no subsidy. Accounting for the additionality problem, Ito (2015) finds that energy conservation subsidies in California did not lead to any conservation in coastal areas (though it did in inland regions).
} 
payments, term lengths, upfront payments, and more - agreed upon between customers and third parties. This entailed sampling and transcribing about 2,000 TPO contracts to build a database of TPO contract terms.

We estimate the pass-through rate of the CSI rebate to post-incentive system prices for both $\mathrm{HO}$ and TPO customers. Intuitively, the main identifying variation that we leverage comes from large and sudden jumps in rebate levels - across utility territories and over time - relative to smooth price trends that control for pricing trends such as declining costs and technology uncertainty. As with any empirical study of a specific market, our strategy yields a pass-through estimate local to the market conditions in California. With that said, the California solar market is large and often predictive of nationwide or even global solar trends. Therefore, results from California should be of interest to policy makers in many states and countries who are increasingly interested in how the benefits of green subsidies accrue across different types of consumers and firms.

We find that pass-through is remarkably high and differs substantially for consumers who buy versus lease solar systems. Consumers who buy capture nearly the full subsidy amount - about 78 cents for every dollar increase in subsidies - while there is more-than-complete pass-through to consumers who lease. For lessees, our estimates imply that a $\$ 1$ increase in subsidies translates, on average, into a decrease in solar system prices of $\$ 1.53$. We thus find that solar subsidies are predominantly or more than fully passed through to consumers, despite popular claims to the contrary. We also conclude that - even as the burden of a subsidy drop (or the benefits of a subsidy increase) shifts from consumers to firms as the market becomes less competitive - consumers likely receive a large majority of the extra surplus when subsidies increase, regardless of the market structure.

The difference in pass-through rates between buyers and lessees is striking considering both markets offer nearly the same product. Nonetheless, several factors could explain this, such as consumer selection and differences in market structure. Perhaps even more surprisingly, however, is that we find substantial over-shifting in the leasing market. It is natural to ask what explains this over-shifting. Imperfect competition combined with "sufficiently convex" demand is a leading explanation, but there exist other conditions under which over-shifting can occur. We formalize pass-through over-shifting as an under-utilized test for market power by outlining alternative explanations that need to be ruled out.

These alternative explanations are uncommon in most markets and certainly unlikely to apply to the solar market. We demonstrate that over-shifting can occur in competitive markets in the presence of Giffen behavior, decreasing marginal costs, nominal pricing rigidities (Conlon and Rao 2016) or - by extending the analysis in Kopczuk et al. (2016) - when firms can inflate their subsidy amounts in a manner unobserved to the econometrician. Such manipulation is nearly impossible in the context of the CSI rebate, although TPO installers have allegedly inflated federal solar tax credits (Greentech Media 2013). These practices do not affect our analysis, however. We also demonstrate that tax salience, while clearly affecting pass-through (Chetty et al. 2009), cannot explain over-shifting in a perfectly competitive market. Hence, except under conditions that are 
unlikely in most markets, over-shifting implies imperfect competition.

Finally, we connect the theory of pass-through over-shifting under imperfect competition-which we argue can be only rationalized by sufficiently convex demand in the setting of the California solar market - with an empirical test of demand curvature. While this may seem to be a natural test to perform in an empirical paper that reports pass-through above unity, earlier papers have not explicitly made this connection. ${ }^{5}$ We estimate demand for solar systems in the HO and TPO markets separately and, subject to a range of caveats, find that the curvature of demand in the solar sector appears broadly consistent with the possibility of over-shifting. This is - to the best of our knowledge - the first empirical test of consistency between over-shifting and demand curvature and allows us to provide supporting evidence for our empirical findings and our conclusion about the presence of market power. The feasibility of such a supporting demand curvature test depends on the availability of sufficiently rich data, which may not be available in all settings.

There is a rich empirical literature on tax incidence and pass-through, with most papers finding pass-through rates between 0 and 100 percent (see, e.g., Nakamura and Zerom 2010; Goldberg and Hellerstein 2013). Studies also occasionally document over-shifting. For example, analyses of alcohol taxes (Young and Bielinska-Kwapisz 2002; Kenkel 2005), cigarette taxes (Barzel 1976; Barnett et al. 1995; Delipalla and O'Donnell 2001), and - in some cases - fuel taxes (Stolper 2016) have found that pass-through exceeds unity. ${ }^{6}$ In fact, more than complete pass-through is actually quite common. Besley and Rosen (1999) study pass-through patterns of transaction taxes for many commodities and find evidence of over-shifting for more than half of them, such as milk, shampoo, and soda.

This paper makes several contributions. First, and most importantly, we show under what conditions a straightforward pass-through estimation can serve as a useful diagnostic test for market power, and how estimating demand convexity — in addition to ruling out alternative explanationscan corroborate such a conclusion. A positive result justifies further investigation by economists and competition authorities, for instance using detailed structural modelling that can shed light on market structure, markups, and the deadweight loss from imperfect competition.

Our pass-through estimates also contribute to the literature on renewable energy subsidies and leasing markets. Pass-through rates serve as important inputs in other calculations such as the incidence of taxes or subsidies under a range of assumptions about competition (Ganapati et al. 2016). Our findings suggest that subsidy incidence falls primarily on the consumer. We are the first to find over-shifting in clean energy markets, and as one of the few papers to estimate how pass-through differs between owners and lessees of the same product, this paper is the first to

\footnotetext{
${ }^{5}$ Several papers (see, e.g., Besley and Rosen (1999) and several more that are cited in the next paragraph) discussbut do not test for-demand convexity as a potential explanation for over-shifting. Stolper (2016) uses measures of market concentration and spatial isolation to explain pass-through patterns, but the paper does not empirically test for demand convexity either.

${ }^{6}$ Marion and Muehlegger (2011) also find that pass-through exceeds unity in gasoline markets, however the result is not statistically distinguishable from 100 percent. Furthermore, while the main finding in Ganapati et al. (2016) is incomplete pass-through in the U.S. manufacturing context, they note that over-shifting also occurs in industries with inelastic demand and/or relatively high markups.
} 
find over-shifting in a leasing context. ${ }^{7}$ Despite the widespread use of leasing, other studies of solar subsidy pass-through have not estimated pass-through for lessees because of data limitations, which we overcome by obtaining TPO contracts (Podolefsky 2013; Dong et al. 2016; Gillingham and Tsvetanov 2017). In fact, to the best of our knowledge, our analysis is the first to differentially estimate pass-through for owners and lessees in any non-property setting. ${ }^{8}$

The paper proceeds as follows. Section 2 lays out the theory of pass-through under perfect and imperfect competition. Section 3 details institutional facts about solar energy subsidies and describes the data that we use. Section 4 discusses our empirical strategy and presents solar subsidy pass-through estimation results and their robustness. In Section 5, we discuss alternative explanations of over-shifting besides market power and conclude that they are highly unlikely in our context. Section 6 describes how we flexibly estimate demand to perform an empirical test of consistency between demand curvature and over-shifting theory, and connect this to our pass-through estimates. We conclude in Section 7.

\section{Theory of Pass-Through and Market Power}

Under the commonly applied simplifying assumptions of perfect competition, upward sloping supply, and downward sloping demand, economic theory predicts that the absolute pass-through of a tax or subsidy to consumers ranges between 0 and 100 percent. However, (local) pass-through varies substantially according to the slopes and shapes of demand and supply curves, as well as the level of market competition. Pass-through even exceeds 100 percent under certain conditions, and as previously noted, such "over-shifting" is not unheard of.

To explore how over-shifting can occur, we begin with a discussion of pass-through theory under the standard assumptions of a competitive market with upward sloping supply and downward sloping demand as a baseline. Both consumers and producers take prices as given and choose quantities that maximize their welfare. Let $p$ be the price paid by consumers. Suppliers pay a perunit tax $t$ and therefore receive price $p-t$. All firms are identical and there is a single market price that equates aggregate demand and competitive supply in equilibrium so that $D(p)=S(p-t)$. We then ask how an increase in the per-unit tax (or analogously, a per-unit subsidy) affects prices. It is common to think of producers directly bearing the cost or benefit and then "passing through" the tax or subsidy indirectly to consumers. We are thus interested in the pass-through rate, $\rho=d p / d t$,

\footnotetext{
${ }^{7}$ The paper also contributes to the small but growing literature on subsidy incidence, which has received less attention than tax incidence, particularly in the context of green technologies. Exceptions include Borenstein and Davis (2016) (distributional equity of clean energy tax credits), Kirwan (2009) (agricultural subsidies) as well as West (2004), Beresteanu and Li (2011), and Sallee (2011) (vehicle subsidies).

${ }^{8}$ Busse et al. (2006), Sallee (2011), Busse et al. (2012), Kaul et al. (2016), and Gulati et al. (2017) estimate pass-through in automobile markets but do not allow for heterogeneous pass-through between buyers and lessees. On the other hand, pass-through has been estimated for those who lease properties and land in the housing and agricultural sectors. Kirwan (2009) examines how renters of farmland capture agricultural subsidies. Nafari (2017) studies residential property tax incidence in owner-occupied and renter-occupied contexts. None of these papers find over-shifting.
} 
or by how much prices paid by consumers rise with a tax increase.

Due to Jenkin (1872), in a competitive market, the pass-through of a tax or subsidy to the prices consumers face is

$$
\rho=\frac{1}{1+\frac{\varepsilon_{D}}{\varepsilon_{S}}},
$$

where $\varepsilon_{D} \equiv-\left(D^{\prime} p / q\right)$ is the elasticity of demand, $\varepsilon_{S} \equiv S^{\prime} p / q$ is the elasticity of supply and $q$ is quantity.

Equation 1 is the classic result demonstrating how pass-through in perfectly competitive markets is bounded between 0 and 100 percent and determined entirely by the relative elasticity of supply and demand. Complete pass-through occurs when either demand is perfectly inelastic or supply is perfectly elastic and zero pass-through occurs when demand is perfectly elastic. In other words, the more inelastic side of the market bears the greater burden of the tax or reaps the larger benefit of the subsidy.

\subsection{Pass-Through in the Presence of Market Power}

We next consider the case of a monopoly. We assume that the monopolist's profit function is concave in quantity and that the cost, $c(q)$, and demand functions are smooth. Revenues are $p(q) q$ and from this we can find marginal revenues as $m r(q)=p(q)+p^{\prime}(q) q$ and marginal cost as $m c(q)=c^{\prime}(q)$. A per-unit tax on producers uniformly raises marginal cost by $t$, or analogously, a per-unit subsidy on producers uniformly reduces marginal cost by $s$. As first shown in Bulow and Pfleiderer (1983) and Seade (1985), and more recently in Weyl and Fabinger (2013), pass-through under monopoly can be calculated by solving the monopolist's optimization problem and then finding the rate at which price changes with marginal cost. The monopolist maximizes profits by choosing quantity such that $m r(q)=m c(q)+t$, and we detail in Appendix A that pass-through can be shown to equal

$$
\rho=\frac{1}{1+\frac{\varepsilon_{D}-1}{\varepsilon_{S}}+\frac{1}{\varepsilon_{m s}}},
$$

where $m s=-p^{\prime} q$, the marginal consumer surplus, is what consumers earn when quantity expands, and $\varepsilon_{m s}=m s / m s^{\prime} q$ is the elasticity of the inverse marginal surplus function. This extra component - as we explain below - measures the curvature of the logarithm of demand.

There are two changes from the pass-through formula under perfect competition (Equation 1). First, $\varepsilon_{D}-1$ has replaced $\varepsilon_{D}$, however this does not introduce any new determinants of passthrough. ${ }^{9}$ Second, more importantly, there is the new term containing the inverse elasticity of

\footnotetext{
${ }^{9}$ The elasticity of demand is never less than one for the case of a monopoly, and so the appropriate elasticity of demand is relative to unity rather than zero.
} 
marginal surplus. This is the key distinctive factor when considering pass-through for a monopolist relative to the case of perfect competition. It is essentially a "convexity parameter" that measures the curvature of (the logarithm of) demand. Weyl and Fabinger (2013) discuss this more extensively, but we can see this using marginal surplus $m s=-p^{\prime} q$ :

$$
(\log D)^{\prime}=\frac{D^{\prime}}{D}=\frac{1}{p^{\prime} q}=-\frac{1}{m s}
$$

where $D \equiv D(p)$ and then

$$
(\log D)^{\prime \prime}=-\frac{1}{\varepsilon_{m s}} \frac{1}{m s^{2}}
$$

From Equation 4 it follows immediately that demand is logarithmically concave (or log-concave) when $1 / \varepsilon_{m s}>0$ and logarithmically convex when $1 / \varepsilon_{m s}<0$. Since the logarithm is a concave function, log-convex demand implies that the original demand function is highly convex (often referred to as superconvex). Hence, all log-convex functions are convex, but not vice versa. One familiar form of log-convex demand is isoelastic demand such as the case of constant elasticity where $\varepsilon_{m s}=-\varepsilon$. Another useful threshold to bear in mind is that if demand is concave, then $1 / \varepsilon_{m s}>1$, and if it is convex, then $1 / \varepsilon_{m s}<1$. We show this in Appendix A.

This demonstrates how pass-through under monopoly does not just depend on the relative elasticities of supply and demand but also on other parameters that define the shape of the demand curve, specifically on whether demand is concave, convex, or very convex. ${ }^{10}$ If we assume constant marginal costs and consider the case of linear demand (i.e., $1 / \varepsilon_{m s}=1$ ), we can see that Equation 2 reduces to one-half since the component containing elasticity of supply drops out (because the elasticity of supply is infinite). When demand is concave and $1 / \varepsilon_{m s}>1$, pass-through decreases so that it is between 0 and 50 percent. Alternatively, when demand is convex and $1 / \varepsilon_{m s}<1$, pass-through increases so that it is more than 50 percent, and it can exceed 100 percent if demand is "convex enough". More specifically, under linear costs, pass-through exceeds unity if and only if $1 / \varepsilon_{m s}<0$ (i.e., when demand is log-convex).

Figure 1 illustrates pass-through for a monopoly with constant marginal costs facing log-convex demand and thus $\rho>1$. We also show cases where over-shifting cannot occur in Appendix Figure C.1. Panel A represents the case of perfect competition, where pass-through is strictly between 0 and 100 percent despite very convex demand. Panel B represents the case of monopoly but with linear demand, where pass-through is always exactly 50 percent.

The threshold requirement of $1 / \varepsilon_{m s}<0$, or simply $\varepsilon_{m s}<0$, for pass-through to exceed unity generalizes to other common models of imperfect competition. As shown in Weyl and Fabinger

\footnotetext{
${ }^{10}$ Bulow and Pfleiderer (1983) and Seade (1985) first emphasized the connection between the elasticity of marginal surplus and demand curvature. See also Katz and Rosen (1985), Stern (1987), and Delipalla and Keen (1992) for additional early theory on over-shifting when demand is sufficiently convex in single-product oligopoly models. Anderson et al. (2001) show that this is also true in an oligopoly with differentiated goods.
} 
Figure 1: Pass-Through Over-Shifting for a Monopolist with Constant Marginal Costs and Constant Elasticity Demand

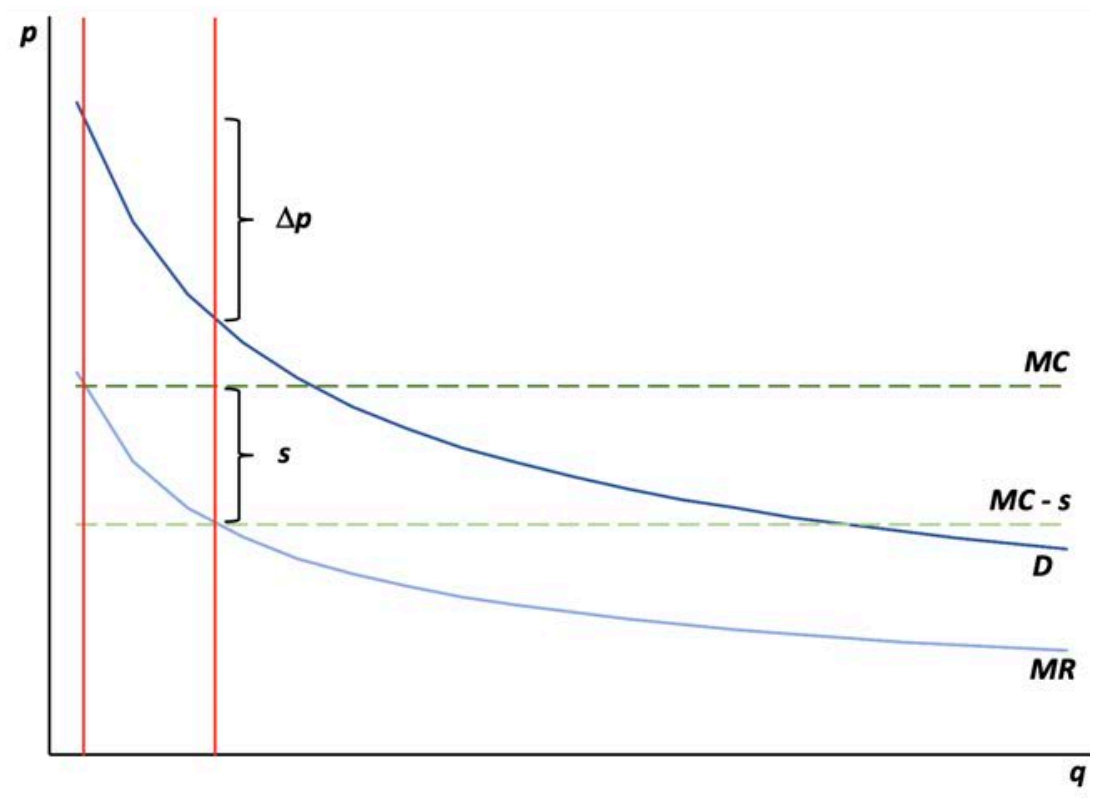

Note: Figure shows the price effect of a subsidy $s$ on the price $p$ set by a monopolist. $M C$ refers to marginal cost, $D$ to demand, and $M R$ to marginal revenue. The constant elasticity parameter is $\epsilon=-0.5$.

(2013), pass-through under symmetric, imperfect competition is

$$
\rho=\frac{1}{1+\frac{\theta}{\varepsilon_{\theta}}+\frac{\varepsilon_{D}-\theta}{\varepsilon_{S}}+\frac{\theta}{\varepsilon_{m s}}},
$$

where $\theta$ is a conduct parameter ranging between zero for perfect competition and one for a pure monopoly. For many standard models of imperfect competition like Cournot, $\theta$ is invariant to changes in $q$, and thus the term $\theta / \varepsilon_{\theta}$ is absent because $1 / \varepsilon_{\theta}=0$. As such, analogous to the case of the monopoly, pass-through exceeds unity if and only if $\varepsilon_{m s}$ is negative (with constant marginal costs). ${ }^{11}$

\subsection{Over-Shifting as a Test for Market Power}

The observation that pass-through can exceed unity is not new. Economists have long understood that over-shifting occurs under many familiar models of imperfect competition when demand is sufficiently convex. However, as we discuss in Section 5, there are other - albeit unlikely - conditions under which pass-through can exceed unity. To the extent that these alternative explanations can

\footnotetext{
${ }^{11}$ The acceptable range of values for $\varepsilon_{m s}$ also should be checked against the second order and stability conditions for the problem to ensure consistency with stable symmetric market equilibrium. We detail these conditions in Appendix A. They imply stricter conditions than $\varepsilon_{m s}<0$ in order to obtain over-shifting.
} 
be carefully ruled out, however, over-shifting implies the existence of market power. ${ }^{12}$ This result has not explicitly appeared in the literature, to our knowledge.

This suggests that estimating pass-through and finding that it over-shifts is an under-utilized test for detecting market power. While more detailed structural modeling can provide important information about market structure, the degree of market power, markups, and the deadweight loss from imperfect competition, such an analysis typically imposes large time, data, and resource demands. Alternatively, estimating pass-through of even industry-wide input costs - such as taxes and subsidies - to prices in a partial equilibrium setting, which is often relatively straightforward, can serve as a useful first diagnostic market power test.

\section{Institutional Background and Data}

\subsection{The California Solar Initiative}

The empirical context examined in this paper is solar energy subsidies, a highly prevalent policy tool used to promote clean energy technologies. We study how they are passed through to the solar system prices consumers face in the context of the California Solar Initiative (CSI). In an ideal experiment, we would consider a market characterized by similar installers that offer similar prices to a homogeneous group of potential solar adopters on systems with identical characteristics (size, performance, solar output, design, etc.). We would then randomly vary rebate amounts across consumer groups. Unsurprisingly, actual solar subsidies are not implemented in this way. However, the CSI program design provides unique and exogenous time and cross-sectional variation that allows us to use sudden changes in subsidy levels to identify pass-through with some additional assumptions.

The CSI program took effect on January 1, 2007 with a 10-year planned budget of $\$ 2.167$ billion (although the program was mostly exhausted by mid-2013) and was available to the customers of California's three major Investor-Owned Utilities (IOUs): San Diego Gas and Electric (SDG\&E), Southern California Edison (SCE), and Pacific Gas and Electric Company (PG\&E). The IOUs cover the vast majority of California's ratepayers, making the CSI program representative of California's solar market. Rebate levels started at $\$ 2.50$ per watt and "stepped down" over ten pre-determined rates based upon cumulative installed capacity in each IOU service region, declining to $\$ 0.20$ per watt over the program lifetime (Figure 2, panel A). This introduced sharp changes in rebate levels (or the per watt value of the subsidy). Figure 2 (panel B) illustrates the CSI rebate level over time and across utilities from 2010 through Q2 2013. Note that the rebate steps change at different times for each IOU. ${ }^{13}$

Figure 2 conveys the essence of our estimation strategy outlined in Section 4. The sharp changes in rebate levels across IOUs and over time provide us with useful price variation, even when we

\footnotetext{
${ }^{12}$ Pass-through will not always exceed unity when there exists market power (e.g., demand must be sufficiently convex), so finding that pass-through is less than 100 percent does not imply the absence of market power.

${ }^{13}$ The timing of subsidy steps depends on solar adoption rates and can vary by utility. PG\&E and SDG\&E exhibit a very similar pattern. SCE was initially lagging behind but almost caught up with the other two utilities by 2013.
} 
Figure 2: Variation in CSI Rebate (\$/Watt) Across IOUs and Over Time

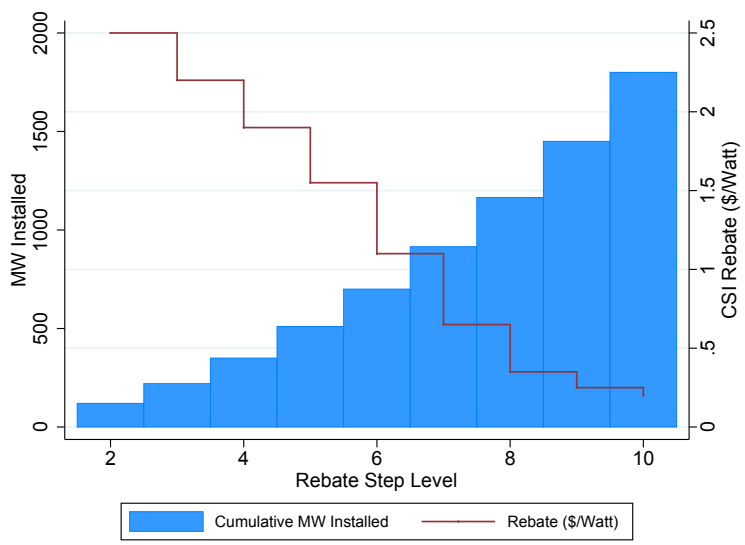

(a) Rebate Levels as a Function of Cumulative Installed Capacity.

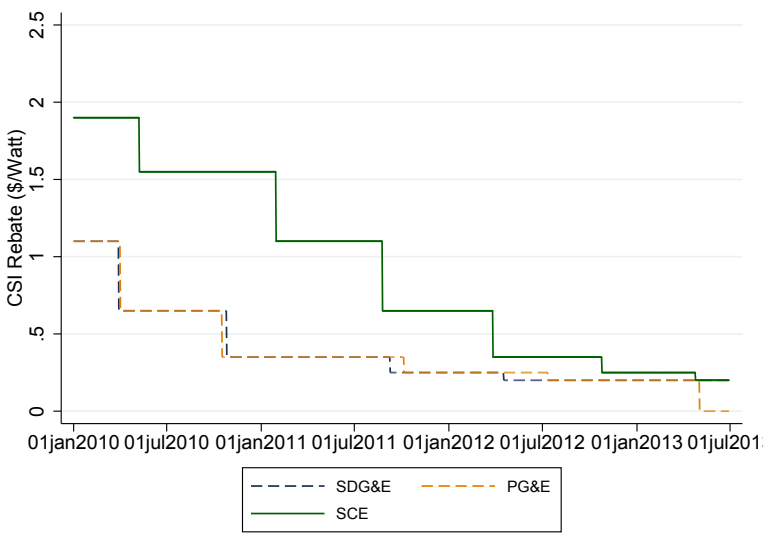

(b) CSI Rebate Levels for California's Three IOUs.

control for a variety of other potential time trends.

\subsection{Host- versus Third-Party Owned Systems and Market Power}

Residential solar customers in California choose to use either HO or TPO, which is analogous to buying versus leasing a consumer product in other markets. This choice has direct implications for solar subsidies, which are nominally directed to the system owner. In the case of HO, residential homeowners own the solar system and all output that it generates over its lifetime. On the other hand, under the TPO model, homeowners sign a lease or power purchase agreement (PPA) with a third-party solar company who then owns the system. In other words, subsidies are directed to homeowners for the case of HO and to solar companies for the case of TPO.

The TPO model for solar was first introduced for residential customers in California in 2007, and it quickly became popular - by 2012, over 70 percent of new systems in the state were installed using TPO options (Figure 3). Under typical TPO contracts, consumers immediately reap the benefits of installing solar (i.e., electricity bill savings) and avoid taking on debt. Third-party financiers secure investor capital and tax equity to purchase solar systems on behalf of residential homeowners who then lease the systems while incurring little or no upfront cost. The TPO providers also offer additional services such as system monitoring and operations and maintenance over the lease term. At the end of the lease term, homeowners typically have the option to purchase the system at fair market value, renew the lease, or remove the system at no extra cost.

Initially, TPO market traction was largely driven by SolarCity, a firm that offered vertically integrated installation and leasing services. Soon afterwards, competitors like Sunrun began offering TPO contracts as well. Various mergers have taken place over time between financing and installation companies (e.g., Sunrun and REC Solar in 2014), leading to an increasing number of vertically integrated firms that have large market shares, including some of the biggest players 
Figure 3: Trend in CSI Rebate Applications by Business Model in California, 2010-Q2 2013

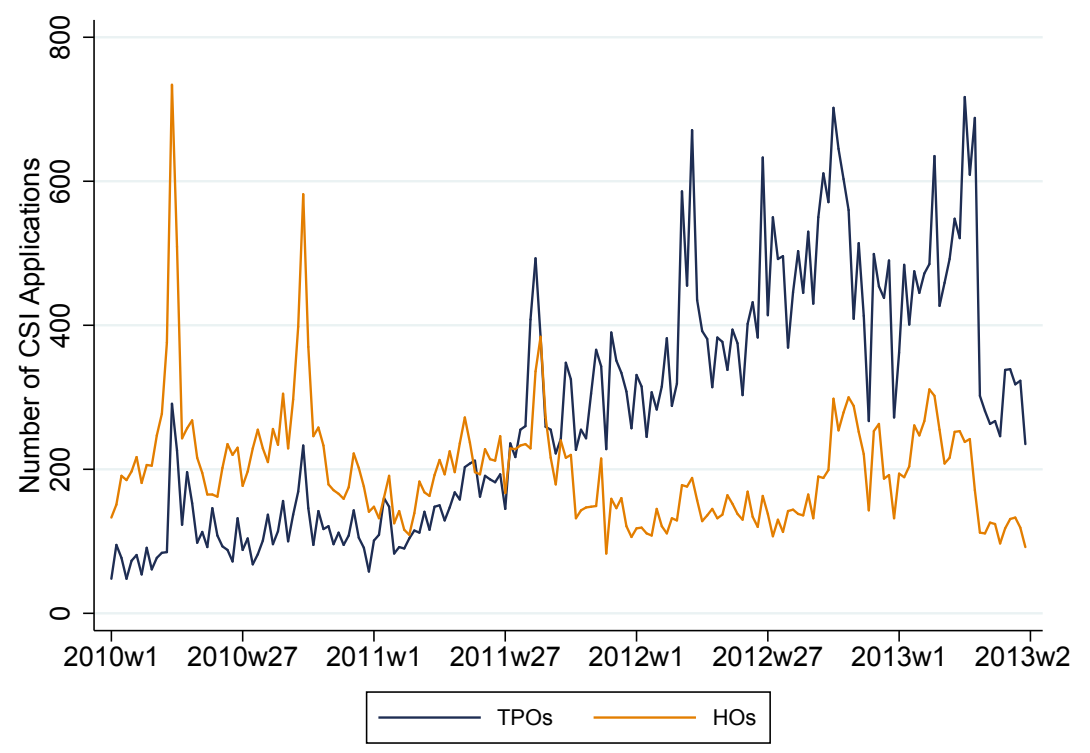

Note: The drop in the spring of 2013 reflects that rebates were exhausted for customers in Pacific Gas \& Electric's territory at the end of April 2013.

for TPO like SolarCity and Vivint (McIntosh and Mandel 2014). As such, although the industry has seen market entrants over time and many companies offer TPO options, the TPO market is mostly dominated by just a few large firms. On the other hand, there are many small independent installers that offer $\mathrm{HO}$ system sales and services. ${ }^{14}$

\subsection{Solar Subsidy and System Data}

We collect solar system-level data from the CSI database, which includes the total amount of rebate received by residential solar adopters. These data also include system characteristics such as size, location, module type, module manufacturer, module model, number of inverters, and installer. This provides us with a rich set of controls. We include additional controls by matching our system-level data to census tract-level demographic data. Details are provided in Appendix B.1.

We include only residential systems in our sample and define the rebate date as the "first reservation request review date", since rebate amounts are determined when the rebate reservation is made as opposed to when the project is completed. Following Hughes and Podolefsky (2015), we view the reservation date as the best approximation of the customer's decision timing. We begin our sample in 2010 due to TPO contract data availability and we end our sample at the end of Q2 2013. This is when subsidy rates had become very low (or exhausted) across IOUs.

The total CSI rebate amounts listed in the database are determined by the rebate rates that

\footnotetext{
${ }^{14}$ The public CSI data that we use in our study suggest that the top 5 TPO companies were responsible for about 56 percent of TPO installations from 2010 through Q2 2013. In contrast, the top 5 HO companies were responsible for just 17 percent of $\mathrm{HO}$ installations.
} 
existed at the time the customer made a reservation through their IOU as well as the system and geographical characteristics that contribute to expected system performance. The rebate application process requires submitting information on system characteristics that determine performance, such as module type, inverter type, system size, installation location, site shading, system orientation, etc. These characteristics determine the system's "design factor", or the expected electrical output of the solar system relative to a reference system. The design factor is multiplied by the rebate rate to find the total subsidy amount. This amount is reported back to the customer, and once the system is connected to the grid, the solar system owner receives a check for the total subsidy amount. We describe a few other steps we took to prepare the data in Appendix B.1.

\subsection{System Price Data}

The effective price of a solar system to a consumer reflects government incentives. These are either factored into the transaction price paid to the installer if the company receives the subsidy, or alternatively, the consumer receives a rebate directly from the government that should be subtracted from the transaction price. Under TPO, contractors negotiate contract terms based upon the rebate they receive and presumably pass through subsidies to consumers to some degree in the form of more favorable contract terms.

The price measure used in this paper, post-incentive price, is the transaction price inclusive of cash rebates and other incentives. Our primary challenge is in obtaining an equivalently measured post-incentive price for TPO and HO systems. The CSI dataset includes "total reported cost" before incentives. This is considered a reliable measure for $\mathrm{HO}$ systems, so the post-incentive price for HO consumers is simply the reported total cost minus incentives. These include the CSI incentive amount as well as a pre-existing federal incentive, the federal investment tax credit (ITC), which provides a 30 percent tax credit to all solar PV system owners.

We do not observe the actual ITC for each consumer. To overcome this, we derive the implied ITC by assuming that it is fully monetized. ${ }^{15}$ For an HO system, the CSI rebate is considered a price reduction for tax credit purposes. Thus, the ITC applies to the after-rebate net price paid by the customer, calculated as

$$
I T C_{H O, i}=0.3 *\left(T C_{H O, i}-C S I_{H O, i}\right)
$$

where $I T C_{H O, i}$ is the federal ITC received by $\mathrm{HO}$ consumer $i, T C_{H O, i}$ is the total pre-incentive system cost reported in CSI, and $C S I_{H O, i}$ is the total CSI rebate amount received. The postincentive price for $\mathrm{HO}$ consumers is then the total reported cost minus CSI and ITC.

\footnotetext{
${ }^{15}$ It is possible that the cost of the system reported to the CSI is not the cost reported on tax forms for ITC purposes. Furthermore, the credit is non-refundable and cannot be carried forward beyond 2016. As such, the customer must have enough tax liability to absorb the credit. Our calculation follows Borenstein (2017) and assumes that the ITC is fully monetized. This likely overstates its value somewhat (Borenstein 2017). However, the ability to monetize the ITC does not affect pass-through for HO because post-incentive prices and the effective CSI rebate both scale with 1 minus the effective ITC rate. See Appendix B.2 for details.
} 
Importantly, the total costs in the CSI database for TPO systems are reported inconsistently. It has been widely recognized that any analyses of CSI data that use reported costs as a proxy for fair market value of TPO systems are "fundamentally flawed" (Greentech Media 2013). They are installer-reported appraised values of the system as opposed to the actual prices consumers pay. Deriving a post-incentive price faced by TPO consumers requires information on the actual TPO contract terms agreed upon between customers and third parties. As such, we construct the post-incentive price for TPO consumers by calculating the (subsidy-inclusive) net present cost (NPC) based upon actual contract terms. This requires data on monthly lease payments or power purchase agreement (PPA) rates, estimated solar production (for PPAs), contract term length, upfront payments, and the annual escalation rate.

We obtained a non-disclosure agreement with the California Public Utilities Commission to gain access to residential TPO contracts signed during 2010-2013. We sampled about 2,000 of the contracts following a stratified sampling strategy described in Appendix B.1. We manually transcribed this set of contracts to build a unique database of TPO contract terms. This provided us with the relevant information needed to calculate the NPC of each contract based upon a standard discounted cash flow methodology. We assume a 7 percent discount rate as a baseline (see Section 4.3 for sensitivity analysis around this assumption), and calculate the NPC as follows:

$$
N P C_{i}=U_{i}+\sum_{y=1}^{t} \frac{\text { payment }_{i y}}{(1+d)^{y}}
$$

where $U_{i}$ is the upfront payment for system $i$, payment $_{i y}$ is the total annual payment in year $y, d$ is the discount rate, and $t$ is the number of years on the contract term.

For leases, annual payments are derived from monthly payment amounts and escalation rates. For PPAs, annual payments are calculated based upon the PPA rate as well as estimated year one production (also provided in the contract) and assuming a 0.5 percent annual output degradation rate over the contract term length (following Jordan and Kurtz (2013)). ${ }^{16}$ For prepaid TPO systems - the case where a TPO agreement was signed but the consumer pays for all monthly payments upfront - the NPC is simply the amount paid upfront.

Like HO consumers, TPO installers were eligible for other existing incentives as well; TPO installers can take advantage of an accelerated depreciation scheme, the Modified Accelerated Cost Recovery System (MACRS), in addition to the ITC. However, there is no need to net out such incentives from the NPC in order to obtain a post-incentive price as we do in the case of $\mathrm{HO}$ systems, because the TPO installers receive all subsidies directly and these are embedded in the final contract price offered to consumers. In other words, the NPC for TPO consumers is already a post-incentive price.

Figure 4 illustrates how post-incentive prices evolved in the California solar market, both for

\footnotetext{
${ }^{16}$ The NPC of PPAs should be interpreted as an "expected" NPC since the payments are based upon estimated production.
} 
HO and TPO consumers. They decline gradually, but more so for HO than for TPO. Given the simultaneously declining path of CSI rebates, pre-incentive prices decrease more rapidly. The difference in time trend for HO versus TPO is one indication that these markets are different and further motivates why we allow pass-through and time trends to vary across contract types.

Figure 4: Post-Incentive Price (\$/Watt) Trends for TPO vs. HO

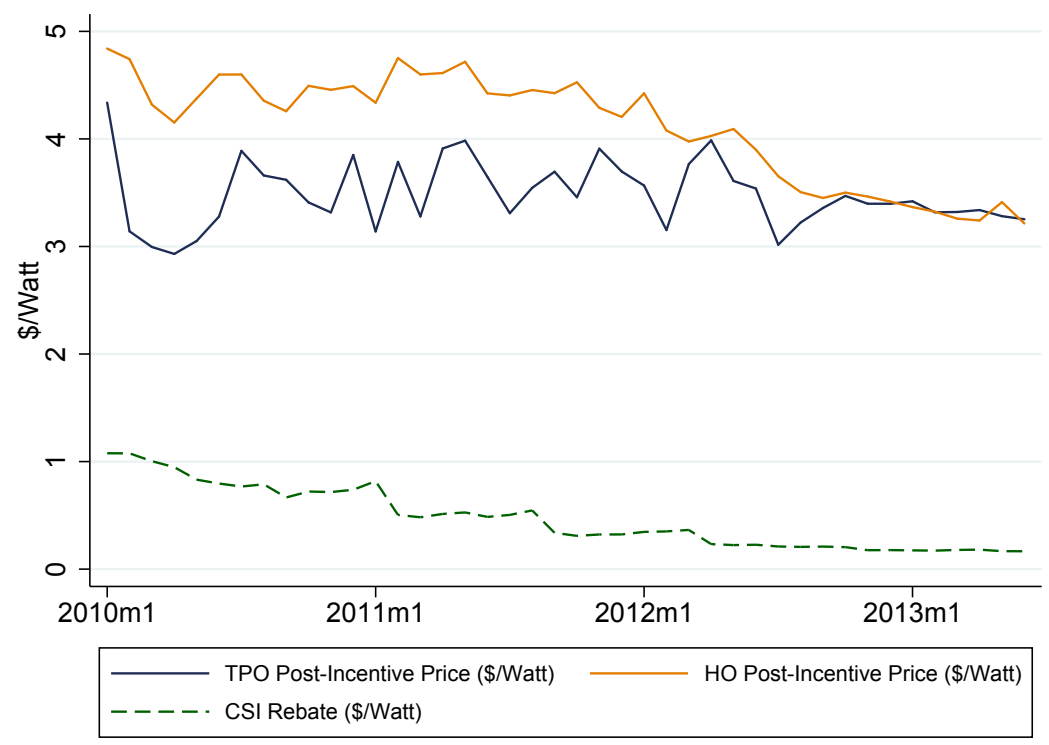

Table 1 presents summary statistics of our data from 2010 through Q2 2013, including the CSI rebate amounts, post-incentive prices, other system characteristics, and demographics. In general, differences for HO and TPO systems are statistically significant but they are relatively modest in terms of their economic magnitudes. Post-incentive prices and CSI rebates tend to be somewhat lower for TPO consumers, which is consistent with HO systems being more prevalent in the early years of our sample when prices and rebates were higher. There are no demographic differences that stand out; the similar (and high) median household incomes for both types of customers suggest that they are similar populations.

\section{Empirical Pass-Through Results}

\subsection{Econometric Framework}

To understand how solar subsidies are passed through to consumers, we estimate the effect of the CSI rebate on post-incentive system prices using the following linear specification that allows for heterogeneous effects between TPO and HO consumers:

(8) $p_{i}=\alpha+\beta_{1}$ rebate $_{i}+\beta_{2}$ rebate $_{i} * T P O_{i}+\beta_{3} T P O_{i}+\mathbf{X}_{i} \phi+\gamma_{j}+\delta_{k}+\varphi_{u}+\omega_{z}+\lambda_{c}+\mu_{t}+\varepsilon_{i}$,

where $p_{i}$ is the post-incentive price $(\$ /$ watt) of system $i$ (henceforth "price"), rebate $i$ is the CSI 
Table 1: Descriptive Statistics of Final Sample, 2010-Q2 2013.

\begin{tabular}{|c|c|c|c|c|c|}
\hline & \multicolumn{3}{|c|}{ Means } & \multicolumn{2}{|c|}{ Standard Deviations } \\
\hline & $\begin{array}{l}\mathrm{HO} \\
(1)\end{array}$ & $\begin{array}{l}\text { TPO } \\
(2)\end{array}$ & $\begin{array}{c}\text { Difference } \\
(3)\end{array}$ & $\begin{array}{c}\mathrm{HO} \\
(4)\end{array}$ & $\begin{array}{c}\text { TPO } \\
(5)\end{array}$ \\
\hline \multicolumn{6}{|l|}{ Panel A. System Characteristics } \\
\hline CSI rebate $(\$ /$ watt $)$ & $\$ 0.505$ & $\$ 0.386$ & $\$ 0.119^{* * *}$ & $\$ 0.398$ & $\$ 0.342$ \\
\hline CSI rebate $(\$)$ & $\$ 2,403$ & $\$ 2,195$ & $\$ 208^{* * *}$ & $\$ 2,261$ & $\$ 2,253$ \\
\hline Post-incentive price (\$/watt) & $\$ 4.13$ & $\$ 3.42$ & $\$ 0.71^{* * *}$ & $\$ 1.379$ & $\$ 0.920$ \\
\hline Post-incentive price $(\$)$ & $\$ 18,975$ & $\$ 18,931$ & $\$ 44$ & $\$ 7,905$ & $\$ 7,408$ \\
\hline System size (watts) & 4,903 & 5,648 & $-745^{* * *}$ & 2,096 & 1,909 \\
\hline System has more than one inverter & $42.8 \%$ & $18.9 \%$ & $23.9 \% * * *$ & $49.5 \%$ & $39.2 \%$ \\
\hline \multicolumn{6}{|l|}{ Panel B. Demographics } \\
\hline Bachelor's degree or higher (\%) & $41.0 \%$ & $38.0 \%$ & $3.0 \% * * *$ & $18.9 \%$ & $18.4 \%$ \\
\hline $\begin{array}{l}\text { Less than high school education } \\
\text { education, age } 18 \text { and older (\%) }\end{array}$ & $9.5 \%$ & $10.2 \%$ & $-0.7 \% * * *$ & $9.0 \%$ & $9.0 \%$ \\
\hline Population density (per sq. mile) & 4,209 & 3,734 & $475^{* * *}$ & 5,630 & 4,122 \\
\hline Housing unit density (per sq. mile) & 1,631 & 1,349 & $282^{* * *}$ & 2,642 & 1,666 \\
\hline Median age of household head & 41.3 & 39.8 & $1.6^{* * *}$ & 7.4 & 7.4 \\
\hline Median number of household members & 2.36 & 2.48 & $-0.12^{* * *}$ & 0.50 & 0.50 \\
\hline Family households (\%) & $73.1 \%$ & $76.3 \%$ & $-3.2 \% * * *$ & $12.8 \%$ & $11.0 \%$ \\
\hline $\begin{array}{l}\text { Median number of family } \\
\text { household members }\end{array}$ & 2.78 & 2.86 & $-0.09 * * *$ & 0.42 & 0.35 \\
\hline Percent owners of all households & $52.4 \%$ & $52.9 \%$ & $-0.5 \% * * *$ & $5.5 \%$ & $5.5 \%$ \\
\hline Median household income $(\$)$ & $\$ 89,752$ & $\$ 90,705$ & $-\$ 953$ & $\$ 33,811$ & $\$ 33,993$ \\
\hline Median house value $(\$)$ & $\$ 520,178$ & $\$ 472,906$ & $\$ 47,272^{* * *}$ & $\$ 250,326$ & $\$ 243,172$ \\
\hline
\end{tabular}

Notes: Demographics are at the census tract level. Dataset contains 32,125 HO observations and 1,306 TPO observations. Asterisks denote ${ }^{*} p<0.10,{ }^{* *} p<0.05,{ }^{* * *} p<0.01$. 
rebate (\$/watt), and $T P O_{i}$ is a business model indicator ( 1 if the system is TPO; 0 otherwise). $\mathbf{X}_{i}$ includes control variables for age, education, income and house value, $\gamma_{j}$ are module manufacturer fixed effects, $\delta_{k}$ are county fixed effects, $\varphi_{u}$ are IOU territory (utility) fixed effects, $\omega_{z}$ are module model fixed effects, $\lambda_{c}$ are installer fixed effects, $\mu_{t}$ are contract type specific weekly quadratic time trends, and $\varepsilon_{i}$ is an error term.

Importantly, we adjust the CSI rebate to correct for its interaction with pre-existing federal incentives (ITC and MACRS) for which solar customers were eligible throughout the sample period. These subsidies mechanically reduce the value of the CSI rebate amount. For example, for HO systems, the ITC is calculated as 30 percent of the after-rebate net consumer price. Hence, a onedollar increase in the CSI rebate is effectively worth only 70 cents, because the extra CSI dollar decreases the value of the ITC by 30 cents. We thus need to multiply the CSI rebate by a correction factor of 0.7 in order to interpret our pass-through coefficient as the price impact of a full one-dollar subsidy increase. More details, including a similar correction for TPO systems, can be found in Appendix B.2. Other papers estimating solar subsidy pass-through have not addressed this issue.

We include a rich set of fixed effects to control for time-invariant mean differences in prices across IOUs, counties, module models, module manufacturers, and installers. Controls include census tract level demographic and housing characteristics. We also include a dummy if more than one inverter is installed, since inverters are an important component of the cost of the system.

Our identification strategy uses smooth weekly quadratic time trends for each contract type (HO, lease, PPA, or prepaid lease). ${ }^{17}$ These trends control for general pricing trends such as declining costs and technological progress. Intuitively, the main identifying variation that we leverage comes from large and sudden jumps in CSI rebate levels - across utilities and over time - relative to smooth price trends (see Figure 2, panel B).

Lastly, we account for consumer selection issues around rebate drop dates. Certain consumers and installers may exhibit strategic timing behavior, as they attempt to apply for the CSI rebate before an anticipated rebate level drop. Although such dates could not be perfectly foreseen, Appendix Figure C.2 shows that some degree of bunching in CSI applications was indeed present, consistent with Hughes and Podolefsky (2015). See Appendix C.2 for more details. If consumers who strategically submit reservation requests differ systematically from those who do not, a comparison of prices just before and after rebate level changes will be based on different types of consumers. For instance, consumers who act strategically might be more price-elastic or better informed. We therefore exclude observations in time windows around the rebate level drop dates (though, reassuringly, we find that our main conclusions hold up even without excluding any observations). ${ }^{18}$

\footnotetext{
${ }^{17}$ Table 5 shows that a less flexible specification that allows time trends to vary only for HO vs. TPO yields very similar results.

${ }^{18}$ On a related note, one might think that the sharp rebate level changes lend naturally to a regression discontinuity design. However, the possibility of economic agents influencing on which side of a threshold they end up complicates the interpretation of a regression discontinuity estimation.
} 


\subsection{Main Results}

Table 2 presents our main results, which measure the effect of a $\$ 1 /$ watt rebate level increase for HO and TPO consumers on post-incentive prices. In panel A, we show our main regression results for varying sizes of the exclusion window to account for consumer selection around rebate drop dates as discussed above. We exclude observations within a symmetric window of two weeks before and after the rebate level drop dates for each IOU in column 2, which we label our baseline specification. We also show the results when no observations are dropped (column 1) and when the size of the exclusion window is increased (columns 3 and 4). In panel B, we show the pass-through coefficients from separate regressions for $\mathrm{HO}$ and TPO.

Table 2: Main Estimates: Pass-Through of Solar Subsidies

\begin{tabular}{|c|c|c|c|c|c|c|c|c|}
\hline & $(1$ & & & $(2)$ & $(3$ & & $(4$ & 4) \\
\hline Panel A. Pooled Regressions & & & & Exclusion & Window: & & & \\
\hline & No & & $+/-2$ Wee & ks (Baseline) & $+/-4$ & Weeks & $+/-6$ & Weeks \\
\hline Incentive & $\begin{array}{r}-0.75 \\
(0.0\end{array}$ & $\begin{array}{l}6^{* * *} \\
555)\end{array}$ & $\begin{array}{r}-0.7 \\
(0\end{array}$ & $\begin{array}{l}78^{* * *} \\
063)\end{array}$ & $\begin{array}{r}-0.74 \\
(0.0\end{array}$ & $\begin{array}{l}6^{* * *} \\
69)\end{array}$ & $\begin{array}{r}-0.77 \\
(0.0\end{array}$ & $\begin{array}{l}1 * * * \\
74)\end{array}$ \\
\hline Incentive $* 1[$ system $=\mathrm{TPO}]$ & $\begin{array}{r}-0.67 \\
(0.2\end{array}$ & $\begin{array}{l}5 * * * \\
210)\end{array}$ & $\begin{array}{r}-0.7 \\
(0\end{array}$ & $\begin{array}{l}50 * * * \\
234)\end{array}$ & $\begin{array}{r}-1.13 \\
(0.2\end{array}$ & $\begin{array}{l}6^{* * *} \\
68)\end{array}$ & $\begin{array}{r}-1.19 \\
(0.2\end{array}$ & $\begin{array}{l}9 * * * \\
293)\end{array}$ \\
\hline $1[$ system $=\mathrm{TPO}]$ & $\begin{array}{r}-0.46 \\
(0.1\end{array}$ & $\begin{array}{l}8^{* * *} \\
172)\end{array}$ & & $\begin{array}{l}378^{*} \\
203)\end{array}$ & $\begin{array}{r}0.0 \\
(0.2\end{array}$ & & & $\begin{array}{l}142 \\
281)\end{array}$ \\
\hline $\begin{array}{l}\text { Number of observations } \\
\text { p-value: HO pass-through }>-1 \\
\text { p-value: TPO pass-through }<-1\end{array}$ & $\begin{array}{r}33 \\
0.0 \\
0.0\end{array}$ & $\begin{array}{l}431 \\
000 \\
21\end{array}$ & & $\begin{array}{l}108 \\
000 \\
013\end{array}$ & $\begin{array}{r}23, \\
0.0 \\
0.0\end{array}$ & $\begin{array}{l}676 \\
00 \\
01\end{array}$ & $\begin{array}{r}20 \\
0.0 \\
0.0\end{array}$ & $\begin{array}{l}070 \\
01 \\
01\end{array}$ \\
\hline Panel B. Separate Regressions & & & & Ownership $S$ & Structure: & & & \\
\hline & $\mathrm{HO}$ & TPO & $\mathrm{HO}$ & TPO & $\mathrm{HO}$ & TPO & $\mathrm{HO}$ & TPO \\
\hline Incentive & $\begin{array}{c}-0.763^{* * *} \\
(0.054)\end{array}$ & $\begin{array}{c}-1.229^{* * *} \\
(0.302)\end{array}$ & $\begin{array}{c}-0.787^{* * *} \\
(0.063)\end{array}$ & $\begin{array}{c}-1.333^{* * *} \\
(0.351)\end{array}$ & $\begin{array}{c}-0.759^{* * *} \\
(0.069)\end{array}$ & $\begin{array}{c}-1.768^{* * *} \\
(0.433)\end{array}$ & $\begin{array}{c}-0.784^{* * *} \\
\quad(0.074)\end{array}$ & $\begin{array}{c}-1.904^{* * *} \\
(0.510)\end{array}$ \\
\hline Number of observations & 32,125 & 1,306 & 27,015 & 1,093 & 22,779 & 897 & 19,318 & 752 \\
\hline $\begin{array}{l}\text { p-value: HO pass-through }>-1 \\
\text { p-value: TPO pass-through }<-1\end{array}$ & 0.000 & 0.225 & 0.000 & 0.172 & 0.000 & 0.038 & 0.002 & 0.039 \\
\hline Controls & $\mathrm{x}$ & $\mathrm{x}$ & $\mathrm{x}$ & $\mathrm{x}$ & $\mathrm{x}$ & $\mathrm{x}$ & $\mathrm{x}$ & $\mathrm{x}$ \\
\hline Utility FE & $\mathrm{x}$ & $\mathrm{x}$ & $\mathrm{x}$ & $\mathrm{x}$ & $\mathrm{x}$ & $\mathrm{x}$ & $\mathrm{x}$ & $\mathrm{x}$ \\
\hline Manufacturer FE & $\mathrm{x}$ & $\mathrm{x}$ & $\mathrm{x}$ & $\mathrm{x}$ & $\mathrm{x}$ & $\mathrm{x}$ & $\mathrm{x}$ & $\mathrm{x}$ \\
\hline Module FE & $\mathrm{x}$ & $\mathrm{x}$ & $\mathrm{x}$ & $\mathrm{x}$ & $\mathrm{x}$ & $\mathrm{x}$ & $\mathrm{x}$ & $\mathrm{x}$ \\
\hline County FE & $\mathrm{x}$ & $\mathrm{x}$ & $\mathrm{x}$ & $\mathrm{x}$ & $\mathrm{x}$ & $\mathrm{x}$ & $\mathrm{x}$ & $\mathrm{x}$ \\
\hline Installer FE & $\mathrm{x}$ & $\mathrm{x}$ & $\mathrm{x}$ & $\mathrm{x}$ & $\mathrm{x}$ & $\mathrm{x}$ & $\mathrm{x}$ & $\mathrm{x}$ \\
\hline Quadratic contract type time trends & $\mathrm{x}$ & $\mathrm{x}$ & $\mathrm{x}$ & $\mathrm{x}$ & $\mathrm{x}$ & $\mathrm{x}$ & $\mathrm{x}$ & $\mathrm{x}$ \\
\hline
\end{tabular}

Notes: Dependent variable is the post-incentive system price per watt. Data cover systems installed in California for consumers who applied for the CSI rebate during the period 2010-Q2 2013. Controls include census tract level demographics and a dummy if there is more than one inverter. A 7 percent discount rate is assumed for the net present cost and MACRS calculations. Standard errors clustered by zip code. In Panel A, the p-value labeled "HO pass-through $>-1$ " is the one-sided p-value of $H_{0}: \beta_{1} \leq-1$ vs. $H_{a}: \beta_{1}>-1$. p-value labeled "TPO pass-through $<-1$ " is the one-sided p-value of $H_{0}: \beta_{1}+\beta_{2} \geq-1$ vs. $H_{a}: \beta_{1}+\beta_{2}<-1$. In panel $\mathrm{B}$, all tests are performed on the single coefficient on the incentive variable. Asterisks denote ${ }^{*} p<0.10,{ }^{* *} p<0.05,{ }^{* * *} p<0.01$ for $H_{0}: \beta=0$ vs. $H_{a}: \beta \neq 0$. 
Throughout all specifications in panel A, we find that the difference in pass-through between TPO and HO consumers is large and highly statistically significant. In our preferred baseline specification (column 2), the pass-through rate is 78 percent for HO and 153 percent for TPO. ${ }^{19}$ When using other exclusion window sizes, pass-through for $\mathrm{HO}$ changes little relative to column 2 (75-77 percent compared to 78 percent). Using a one-sided test, we always reject that pass-through is at least complete, which provides strong evidence for incomplete - but still high - pass-through for HO (see row "p-value: HO pass-through $>-1$ "). The estimates for TPO range from 143-197 percent compared to 153 percent. Pass-through for TPO is statistically and economically greater than 100 percent, providing evidence of substantial pass-through over-shifting (see row "p-value: TPO pass-through $<-1$ "). ${ }^{20}$ The coefficient estimate on the TPO indicator captures time-invariant factors that account for price differences between TPO and HO.

The pass-through estimates from separate regressions in panel B are similar in magnitude to the pooled regression results in panel A, however the estimates for TPOs are somewhat noisier. In our baseline specification, pass-through for TPOs is 133 percent (and not statistically greater than 100 percent) when separated versus 153 percent (and statistically greater than 100 percent) when pooled (see panel A). Note that TPO pass-through in panel B is statistically greater than 100 percent when widening the exclusion window in columns 3 and 4 (one-sided p-values are 0.038 and 0.039 , respectively); from that perspective, our baseline specification is a conservative choice.

The conclusions from panels A and B are similar. We maintain the pooled regression specifications throughout the remainder of the paper - the benefit of efficiency from pooling the data is appealing in this setting, especially given the somewhat limited sample of TPOs.

In summary, our main estimates show that pass-through for solar systems is strikingly high. They also demonstrate significant over-shifting for TPO systems. We discuss and interpret these findings in more detail in the following sections, but first we turn to showing the robustness of our estimates.

\subsection{Robustness Checks}

One critical assumption of our identification strategy is that price trends are smooth over time except for sudden changes in the CSI rebate. To be more confident that our results are not sensitive to the degree of flexibility of the time trend, we estimate additional specifications with more and less flexible contract type specific weekly time trends. We also add utility quadratic time trends to account for the possibility that time-varying factors differ between utility regions. These results are presented in Table 3.

\footnotetext{
${ }^{19}$ Our estimate for HO systems is similar to pass-through rates found in other studies of HO markets, providing additional confidence in our estimation strategy. Gillingham and Tsvetanov (2017) find a pass-through rate of 84 percent in Connecticut and Dong et al. (2016) find nearly 100 percent pass-through in California. Podolefsky (2013) finds a very low pass-through rate for a different type of incentive (the solar ITC). None of these studies examine TPO markets.

${ }^{20}$ When clustering standard errors by county, TPO pass-through is still statistically greater than 100 percent: the one-sided p-value of a test that there is no TPO pass-through overshifting is 0.016 , only slightly higher than the reported 0.013 in panel A, column 2 .
} 
Table 3: Sensitivity of Pass-Through Estimates to Time Trend Flexibility

\begin{tabular}{|c|c|c|c|c|c|c|c|}
\hline & (1) & $(2)$ & (3) & (4) & (5) & (6) & (7) \\
\hline Incentive & $\begin{array}{c}-0.871^{* * *} \\
(0.059)\end{array}$ & $\begin{array}{c}-0.778^{* * *} \\
(0.063)\end{array}$ & $\begin{array}{c}-0.754^{* * *} \\
(0.064)\end{array}$ & $\begin{array}{c}-0.729 * * * \\
(0.064)\end{array}$ & $\begin{array}{c}-0.761^{* * *} \\
(0.065)\end{array}$ & $\begin{array}{c}-0.696^{* * *} \\
(0.064)\end{array}$ & $\begin{array}{c}-1.009^{* * *} \\
(0.102)\end{array}$ \\
\hline Incentive $^{*} 1[$ system $=\mathrm{TPO}]$ & $\begin{array}{c}-0.890^{* * *} \\
(0.239)\end{array}$ & $\begin{array}{c}-0.750^{* * *} \\
(0.234)\end{array}$ & $\begin{array}{c}-0.660 * * * \\
(0.236)\end{array}$ & $\begin{array}{c}-0.662^{* * *} \\
(0.235)\end{array}$ & $\begin{array}{c}-0.749^{* * *} \\
(0.236)\end{array}$ & $\begin{array}{c}-0.779 * * * \\
(0.236)\end{array}$ & $\begin{array}{c}-0.824^{* * *} \\
(0.237)\end{array}$ \\
\hline $1[$ system $=\mathrm{TPO}]$ & $\begin{array}{l}-0.135 \\
(0.161)\end{array}$ & $\begin{array}{c}-0.378^{*} \\
(0.203)\end{array}$ & $\begin{array}{c}-0.826^{* * *} \\
(0.243)\end{array}$ & $\begin{array}{c}-0.815^{* * *} \\
(0.284)\end{array}$ & $\begin{array}{l}-0.447 \\
(0.327)\end{array}$ & $\begin{array}{c}-0.524^{*} \\
(0.287)\end{array}$ & $\begin{array}{c}-0.378^{*} \\
(0.204)\end{array}$ \\
\hline
\end{tabular}

\begin{tabular}{|c|c|c|c|c|c|c|c|}
\hline Controls & $\mathrm{x}$ & $\mathrm{x}$ & $\mathrm{x}$ & $\mathrm{x}$ & $\mathrm{x}$ & $\mathrm{x}$ & $\mathrm{x}$ \\
\hline Utility FE & $\mathrm{x}$ & $\mathrm{x}$ & $\mathrm{x}$ & $\mathrm{x}$ & $\mathrm{x}$ & $\mathrm{x}$ & $\mathrm{x}$ \\
\hline Manufacturer FE & $\mathrm{x}$ & $\mathrm{x}$ & $\mathrm{x}$ & $\mathrm{x}$ & $\mathrm{x}$ & $\mathrm{x}$ & $\mathrm{x}$ \\
\hline Module FE & $\mathrm{x}$ & $\mathrm{x}$ & $\mathrm{x}$ & $\mathrm{x}$ & $\mathrm{x}$ & $\mathrm{x}$ & $\mathrm{x}$ \\
\hline County FE & $\mathrm{x}$ & $\mathrm{x}$ & $\mathrm{x}$ & $\mathrm{x}$ & $\mathrm{x}$ & $\mathrm{x}$ & $\mathrm{x}$ \\
\hline Installer FE & $\mathrm{x}$ & $\mathrm{x}$ & $\mathrm{x}$ & $\mathrm{x}$ & $\mathrm{x}$ & $\mathrm{x}$ & $\mathrm{x}$ \\
\hline Linear contract type time trends & $\mathrm{x}$ & & & & & & \\
\hline Quadratic contract type time trends & & $\mathrm{x}$ & & & & & $\mathrm{x}$ \\
\hline Cubic contract type time trends & & & $\mathrm{x}$ & & & & \\
\hline Quartic contract type time trends & & & & $\mathrm{x}$ & & & \\
\hline Quintic contract type time trends & & & & & $\mathrm{x}$ & & \\
\hline Quarter*year*contract type FE & & & & & & $\mathrm{x}$ & \\
\hline Utility quadratic time trends & & & & & & & $\mathrm{x}$ \\
\hline Number of observations & 28,108 & 28,108 & 28,108 & 28,108 & 28,108 & 28,108 & 28,108 \\
\hline p-value: HO pass-through $>-1$ & 0.015 & 0.000 & 0.000 & 0.000 & 0.000 & 0.000 & 0.536 \\
\hline p-value: TPO pass-through $<-1$ & 0.001 & 0.013 & 0.042 & 0.051 & 0.017 & 0.025 & 0.001 \\
\hline
\end{tabular}

Notes: Dependent variable is the post-incentive system price per watt. Data cover systems installed in California for consumers who applied for the CSI rebate during the period 2010-Q2 2013. Controls include census tract level demographics and a dummy if there is more than one inverter. A 7 percent discount rate is assumed for the net present cost and MACRS calculations. Standard errors clustered by zip code. p-value labeled "HO pass-through $>-1$ " is the one-sided p-value of $H_{0}: \beta_{1} \leq-1$ vs. $H_{a}: \beta_{1}>-1$. p-value labeled "TPO pass-through $<-1$ " is the one-sided p-value of $H_{0}: \beta_{1}+\beta_{2} \geq-1$ vs. $H_{a}: \beta_{1}+\beta_{2}<-1$. Asterisks denote ${ }^{*} p<0.10,{ }^{* *} p<0.05,{ }^{* * *} p<0.01$ for $H_{0}: \beta=0$ vs. $H_{a}: \beta \neq 0$.

We find that the magnitude and significance of our estimates are stable at different levels of time trend flexibility (columns 1-5; baseline estimates in column 2). We also add a specification in which weekly polynomial time trends are replaced with quarter by year fixed effects for each contract type (column 6). This hardly affects our pass-through estimates. Adding utility quadratic time trends to the baseline specification slightly increases pass-through. The final two rows indicate that there is incomplete pass-through for HO for all but one specification; TPO pass-through is always significantly above 100 percent.

We also test if our estimates are sensitive to the discount rate assumption used in the TPO contract NPC calculations. We estimate pass-through assuming discount rates ranging from 2 to 12 percent. The pass-through estimates are stable across specifications (see Table 4; baseline estimates in column 3). They are slightly higher when assuming a lower discount rate and slightly lower when assuming a higher discount rate, but overall the discount rate affects pass-through only modestly. As anticipated, however, the sign of the TPO dummy coefficient is sensitive to the discount rate choice. As we are interested in pass-through, we do not need to take a strong stance on the correct discount rate. 
Table 4: Sensitivity of Pass-Through Estimates to the Discount Rate

\begin{tabular}{|c|c|c|c|c|c|}
\hline & $(1)$ & $(2)$ & $(3)$ & $(4)$ & $(5)$ \\
\hline & $\begin{array}{l}2 \% \text { Discount } \\
\text { Rate }\end{array}$ & $\begin{array}{l}4 \% \text { Discount } \\
\text { Rate }\end{array}$ & $\begin{array}{l}\text { 7\% Discount } \\
\text { Rate }\end{array}$ & $\begin{array}{l}9 \% \text { Discount } \\
\text { Rate }\end{array}$ & $\begin{array}{l}12 \% \text { Discount } \\
\text { Rate }\end{array}$ \\
\hline Incentive & $\begin{array}{c}-0.775^{* * *} \\
(0.065)\end{array}$ & $\begin{array}{c}-0.776^{* * *} \\
(0.064)\end{array}$ & $\begin{array}{c}-0.778^{* * *} \\
(0.063)\end{array}$ & $\begin{array}{c}-0.779 * * * \\
(0.063)\end{array}$ & $\begin{array}{c}-0.779 * * * \\
(0.063)\end{array}$ \\
\hline Incentive $* 1[$ system $=\mathrm{TPO}]$ & $\begin{array}{c}-0.904^{* *} \\
(0.357)\end{array}$ & $\begin{array}{c}-0.830^{* * *} \\
(0.293)\end{array}$ & $\begin{array}{c}-0.750 * * * \\
(0.234)\end{array}$ & $\begin{array}{c}-0.710^{* * *} \\
(0.211)\end{array}$ & $\begin{array}{c}-0.664^{* * *} \\
(0.192)\end{array}$ \\
\hline $1[$ system $=\mathrm{TPO}]$ & $\begin{array}{c}0.684^{* *} \\
(0.316)\end{array}$ & $\begin{array}{c}0.183 \\
(0.258)\end{array}$ & $\begin{array}{c}-0.378^{*} \\
(0.203)\end{array}$ & $\begin{array}{c}-0.661^{* * *} \\
(0.181)\end{array}$ & $\begin{array}{c}-0.990 * * * \\
(0.162)\end{array}$ \\
\hline Controls & $\mathrm{x}$ & $\mathrm{x}$ & $\mathrm{x}$ & $\mathrm{x}$ & $\mathrm{x}$ \\
\hline Utility FE & $\mathrm{x}$ & $\mathrm{x}$ & $\mathrm{x}$ & $\mathrm{x}$ & $\mathrm{x}$ \\
\hline Manufacturer FE & $\mathrm{x}$ & $\mathrm{x}$ & $\mathrm{x}$ & $\mathrm{x}$ & $\mathrm{x}$ \\
\hline Module FE & $\mathrm{x}$ & $\mathrm{x}$ & $\mathrm{x}$ & $\mathrm{x}$ & $\mathrm{x}$ \\
\hline County FE & $\mathrm{x}$ & $\mathrm{x}$ & $\mathrm{x}$ & $\mathrm{x}$ & $\mathrm{x}$ \\
\hline Installer FE & $\mathrm{x}$ & $\mathrm{x}$ & $\mathrm{x}$ & $\mathrm{x}$ & $\mathrm{x}$ \\
\hline Quadratic contract type time trends & $\mathrm{x}$ & $\mathrm{x}$ & $\mathrm{x}$ & $\mathrm{x}$ & $\mathrm{x}$ \\
\hline Number of observations & 28,108 & 28,108 & 28,108 & 28,108 & 28,108 \\
\hline
\end{tabular}

Notes: Dependent variable is the post-incentive system price per watt. Data cover systems installed in California for consumers who applied for the CSI rebate during the period 2010-Q2 2013. Controls include census tract level demographics and a dummy if there is more than one inverter. A 2-12 percent discount rate is assumed for the net present cost and MACRS calculations. Standard errors clustered by zip code. Asterisks denote ${ }^{*} p<0.10,{ }^{* *} p<0.05,{ }^{* * *} p<0.01$.

We perform a number of further robustness checks in Table 5. Column 1 shows that the estimates are almost identical when we include time trends that differentiate between HO vs. TPO only, rather than allowing separate trends for leases, PPAs and prepaid leases. In column 2, we account for the possibility that there are solar panel manufacturer-specific time-varying factors that affect pricing, for example for foreign-based vs. domestic manufacturers. The results show that our results are robust to interacting manufacturer and contract type specific time trends.

We further explore robustness by using propensity score matching to compare differences in pass-through between matched TPO and HO systems sold in similar markets. The propensity score matching helps address the concern that the choice between HO and TPO is not as good as randomly assigned relative to other determinants of prices. ${ }^{21}$ We match on the system and census tract level demographic controls used above as well as the utility region. The results are similar to the main estimates, with pass-through for HO slightly below 100 percent and over-shifting for TPO (column 3). The degree of over-shifting for both HO and TPO is about 10 percent higher than in our baseline specification.

It is possible that our pass-through estimates vary over time because $\mathrm{HO}$ installations are frontloaded to earlier years in our sample and market conditions can change over time. We therefore ran a version of our regression in which we allow pass-through to vary in the first and second half of the

\footnotetext{
${ }^{21} \mathrm{~A}$ related issue is that there might be household-specific unobservables that create a correlation between $\mathrm{HO} / \mathrm{TPO}$ and price. Propensity score matching can only partially alleviate this concern, although the results in Table 5 below are reassuring.
} 
Table 5: Robustness Checks of Pass-Through Estimates

\begin{tabular}{|c|c|c|c|c|c|c|c|}
\hline & $(1)$ & $(2)$ & $(3)$ & $(4)$ & $(5)$ & $(6)$ & $(7)$ \\
\hline & $\begin{array}{l}\text { HO vs. TPO } \\
\text { Time Trends }\end{array}$ & $\begin{array}{c}\text { Manufacturer by } \\
\text { Contract Type } \\
\text { Time Trends }\end{array}$ & $\begin{array}{c}\text { Propensity } \\
\text { Score Matching }\end{array}$ & $\begin{array}{c}\text { Two Time } \\
\text { Periods }\end{array}$ & $\begin{array}{c}\text { Low } 25 \% \\
\text { Corporate } \\
\text { Tax Rate }\end{array}$ & $\begin{array}{l}\text { High } 35 \% \\
\text { Corporate } \\
\text { Tax Rate }\end{array}$ & $\begin{array}{l}\text { Electricity } \\
\text { Rate } \\
\text { Controls }\end{array}$ \\
\hline Incentive & $\begin{array}{c}-0.779 * * * \\
(0.064)\end{array}$ & $\begin{array}{c}-0.757^{* * *} \\
(0.063)\end{array}$ & $\begin{array}{c}-0.677^{* *} \\
(0.274)\end{array}$ & $\begin{array}{c}-0.777 * * * \\
(0.063)\end{array}$ & $\begin{array}{c}-0.789^{* * *} \\
(0.063)\end{array}$ & $\begin{array}{c}-0.789 * * * \\
(0.063)\end{array}$ & $\begin{array}{c}-0.946^{* * *} \\
(0.074)\end{array}$ \\
\hline $\begin{array}{l}\text { Incentive } \\
\quad * 1[\text { system }=\mathrm{TPO}]\end{array}$ & $\begin{array}{c}-0.799^{* * *} \\
(0.274)\end{array}$ & $\begin{array}{c}-0.587^{* *} \\
(0.236)\end{array}$ & $\begin{array}{c}-0.887^{* *} \\
(0.352)\end{array}$ & $\begin{array}{c}-0.779 * * * \\
(0.249)\end{array}$ & $\begin{array}{c}-0.489 * * \\
(0.196)\end{array}$ & $\begin{array}{c}-0.950 * * * \\
(0.265)\end{array}$ & $\begin{array}{c}-0.812^{* * *} \\
(0.236)\end{array}$ \\
\hline $\begin{array}{l}\text { Incentive } \\
\quad * 1 \text { [second half] }\end{array}$ & & & & $\begin{array}{l}-0.014 \\
(0.081)\end{array}$ & & & \\
\hline $\begin{array}{l}\text { Incentive } \\
\quad * 1[\text { system }=\mathrm{TPO}] \\
\quad * 1[\text { second half }]\end{array}$ & & & & $\begin{array}{c}0.208 \\
(0.443)\end{array}$ & & & \\
\hline $1[$ system $=\mathrm{TPO}]$ & $\begin{array}{l}-0.244 \\
(0.235)\end{array}$ & $\begin{array}{l}-0.469^{*} \\
(0.247)\end{array}$ & $\begin{array}{c}0.154 \\
(0.294)\end{array}$ & $\begin{array}{l}-0.345 \\
(0.224)\end{array}$ & $\begin{array}{l}-0.375^{*} \\
(0.201)\end{array}$ & $\begin{array}{l}-0.376^{*} \\
(0.201)\end{array}$ & $\begin{array}{l}-0.377^{*} \\
(0.203)\end{array}$ \\
\hline Controls & $\mathrm{x}$ & $\mathrm{x}$ & $\mathrm{x}$ & $\mathrm{x}$ & $\mathrm{x}$ & $\mathrm{x}$ & $\mathrm{x}$ \\
\hline Utility FE & $\mathrm{x}$ & $\mathrm{x}$ & $\mathrm{x}$ & $\mathrm{x}$ & $\mathrm{x}$ & $\mathrm{x}$ & $\mathrm{x}$ \\
\hline Manufacturer FE & $\mathrm{x}$ & $\mathrm{x}$ & $\mathrm{x}$ & $\mathrm{x}$ & $\mathrm{x}$ & $\mathrm{x}$ & $\mathrm{x}$ \\
\hline Module FE & $\mathrm{x}$ & $\mathrm{x}$ & $\mathrm{x}$ & $\mathrm{x}$ & $\mathrm{x}$ & $\mathrm{x}$ & $\mathrm{x}$ \\
\hline County FE & $\mathrm{x}$ & $\mathrm{x}$ & $\mathrm{x}$ & $\mathrm{x}$ & $\mathrm{x}$ & $\mathrm{x}$ & $\mathrm{x}$ \\
\hline Installer FE & $\mathrm{x}$ & $\mathrm{x}$ & $\mathrm{x}$ & $\mathrm{x}$ & $\mathrm{x}$ & $\mathrm{x}$ & $\mathrm{x}$ \\
\hline Electricity rate controls & & & & & & & $\mathrm{x}$ \\
\hline $\begin{array}{l}\mathrm{HO} \text { vs. TPO quadratic } \\
\text { time trends }\end{array}$ & $\mathrm{x}$ & & & & & & \\
\hline $\begin{array}{l}\text { Manuf. by contr. type } \\
\text { quadratic time trends }\end{array}$ & & $\mathrm{x}$ & & & & & \\
\hline $\begin{array}{l}\text { Quadratic contr. type } \\
\text { time trends }\end{array}$ & & & $\mathrm{x}$ & $\mathrm{x}$ & $\mathrm{x}$ & $\mathrm{x}$ & $\mathrm{x}$ \\
\hline Number of observations & 28,108 & 28,108 & 28,108 & 28,108 & 28,108 & 28,108 & 28,108 \\
\hline
\end{tabular}

Notes: Dependent variable is the post-incentive system price per watt. Data cover systems installed in California for consumers who applied for the CSI rebate during the period 2010-Q2 2013. Controls include census tract level demographics and a dummy if there is more than one inverter. A 7 percent discount rate is assumed for the net present cost and MACRS calculations. Matching in column 3 based upon the controls listed above and the utility region. Electricity rate controls include each IOU's rates for the three highest tiers at the location and date of the CSI application. Standard errors clustered by zip code. Asterisks denote ${ }^{*} p<0.10,{ }^{* *} p<0.05,{ }^{* * *} p<0.01$. 
sample period. Column 4 shows that our main conclusions hold for both time periods. TPO passthrough in the second period is somewhat lower. In columns 5 and 6 , we check the robustness of our results to the corporate tax rate assumption since smaller firms face somewhat lower corporate tax rates. We vary the corporate tax rate assumption between 25 and 35 percent and find the expected pattern of lower (higher) TPO pass-through under lower (higher) tax rate assumptions; TPO pass-through still over-shifts even when assuming a tax rate of 25 percent, which we argue is too low. ${ }^{22}$ Finally, we add electricity rates as controls, based on location and date at which the household applied for the CSI rebate. Higher electricity prices increase electricity bill savings realized from solar adoption and hence may affect solar panel prices.

Overall, the various sensitivity and robustness checks in Tables 3-5 show that our results are stable across specifications in significance and magnitude. ${ }^{23}$ We consistently find pass-through below 100 percent for $\mathrm{HO}$ and above 100 percent for TPO. This is reassuring and provides additional confidence in our pass-through estimates. The high pass-through estimates also lead us to conclude that - even as the burden of a subsidy drop (or the benefits of a subsidy increase) shifts from consumers to firms as the market moves from perfect to imperfect competition-consumers likely receive a large majority of the extra surplus when subsidies increase. Using the incidence bounds in Ganapati et al. (2016), we calculate that the consumer share of the burden for TPO is bounded between 60 and 153 percent as the market moves from monopoly to perfect competition; incidence for HOs is bounded between 44 and 78 percent. Although consumers receive the majority of the extra surplus from increased subsidies even under most forms of imperfect competition, total surplus in such markets will be lower than in competitive markets, which ultimately hampers the speed of solar adoption.

\section{Alternative Explanations}

In Section 2, we discuss how the presence of market power can theoretically explain over-shifting. While there are several alternative explanations for more-than-complete pass-through besides imperfect competition, such conditions are uncommon in most markets and could be considered special cases. We discuss them in this section and argue that they are also unlikely to occur in solar markets. We also discuss how one phenomenon that is widely known to affect pass-through, tax salience, cannot explain over-shifting in a competitive market.

Giffen Behavior.-Equation 1 demonstrates how Giffen behavior, $\varepsilon_{D}<0$, could lead to over-

\footnotetext{
${ }^{22}$ The marginal corporate tax rate in the U.S. differs by a firm's taxable income and varies between 34-39 percent for firms with taxable income above $\$ 75,000$. Corporate tax rates are lower for firms with very low taxable income: 15 percent between $\$ 0-\$ 50,000 ; 25$ percent between $\$ 50,000-\$ 75,000$. As the leasing market is dominated by a couple of large firms, our baseline assumption of 30 percent appears conservative, if anything. An average corporate tax rate of 25 percent is almost certainly too low.

${ }^{23}$ We also interacted HO vs. TPO pass-through with an indicator of market concentration, defined as "less" vs. "more" competition based on the median Herfindahl-Hirschman Index at the zip code (or county) level. The results are consistent with theory but lack statistical power: pass-through is higher in less competitive markets and this effect is stronger for TPO than for HO. Results available on request.
} 
shifting. However, Giffen goods are strongly inferior goods (i.e., goods in very high demand by low-income consumers), while the household income among solar adopters strongly suggests that solar systems are luxury goods (Table 1). Furthermore, empirical evidence of upward sloping demand is extremely sparse; the literature so far has found evidence exclusively in the developing country context. ${ }^{24}$ For the U.S. residential solar market, empirical estimates of the price elasticity of solar systems show that solar markets are indeed characterized by the expected downward sloping demand curves (e.g., Gillingham and Tsvetanov (2017)). Our own demand elasticities in Section 6, while admittedly imprecise, confirm this finding. We conclude that Giffen behavior is unreasonable for solar markets and indeed highly unlikely in most markets.

Salience.-We know that tax salience affects pass-through from Chetty et al. (2009). However, we now show that salience cannot explain over-shifting under perfect competition. Chetty et al. (2009) show that consumers underreact to taxes that are not salient. ${ }^{25}$ In their experiment, consumers make purchasing decisions based on the pre-tax posted price, but they end up paying a tax-inclusive price at the supermarket's register. Analogously, consumers may underreact to subsidies if they are not salient.

To investigate whether tax (or subsidy) salience can explain over-shifting, we first discuss how imperfect salience affects pass-through. We follow Chetty et al. (2009)'s derivation of pass-through that allows for salience effects (and other optimization errors) with respect to taxes and refer to that paper for details. Let $\hat{p}$ denote a good's pre-tax price and assume $t$ is a per-unit tax so that the tax-inclusive price is $p=\hat{p}+t . Z$ denotes wealth of the representative consumer. Under perfect competition, the market-clearing price $\hat{p}$ satisfies $D(\hat{p}, t, Z)=S(\hat{p})$ and implicit differentiation of this yields the pass-through to consumers as

$$
\frac{d p}{d t}=1+\frac{d \hat{p}}{d t}=\frac{\varepsilon_{S}+(1-\eta) \varepsilon_{D}}{\varepsilon_{S}+\varepsilon_{D}},
$$

where $\eta$ is the degree to which agents under-react to the tax $t .{ }^{26}$ When a tax or subsidy is perfectly salient, or $\eta=1$, Equation 9 is identical to the standard pass-through under perfect competition (Equation 1). When $\eta=0$ and the tax or subsidy is fully non-salient (i.e., consumers completely ignore the tax or subsidy), a new positive term enters the numerator of the pass-through formula. Hence, the pass-through of a tax increases as salience decreases. Since $d p / d t=-d p / d s$, the passthrough of a subsidy also increases with lower salience - consumers underreact to the subsidy and their ex-post subsidy-inclusive price ends up being lower.

\footnotetext{
${ }^{24}$ Until Jensen and Miller (2008)'s demand estimation for dietary staples among extremely poor households in China, there were no well-identified empirical papers demonstrating the existence of markets with upward sloping demand. To our knowledge, the existence of Giffen behavior has not been shown to exist in any other markets since, either.

${ }^{25}$ We follow Chetty et al. (2009) in using the term "tax salience" to refer to the visibility of the tax-inclusive price.

${ }^{26}$ Chetty et al. (2009)'s original formulation multiplies the $\varepsilon_{S}$ terms by $p / \hat{p}$, however we follow most of the literature in assuming small changes in the tax/subsidy for consistency with our main analysis in Section 2 , and thus $p / \hat{p} \approx 1$.
} 
From Equation 9 it becomes clear that salience cannot explain over-shifting in a perfectly competitive market; pass-through will be strictly bound between 0 and 100 percent for $0 \leq \eta \leq 1 .^{27}$ As such, even under imperfect salience, over-shifting still implies imperfect competition.

Nonetheless, although limited salience cannot explain over-shifting, differences in the salience of the CSI rebate between HO and TPO could provide one of many possible reasons why their pass-through rates differ. We now argue that limited salience is unlikely to describe either solar market in California. First, consider the case of TPO, where companies receive the CSI rebates, list rebate amounts on customer TPO contracts, and then quote final contract terms so that consumers see prices that fully embed the subsidies. This makes the tax-inclusive price in this market fully salient to consumers. They are not surprised ex-post by a rebate check that they receive some time after purchasing the solar system.

Next, consider the case for HO customers. In this market, the host owner receives the rebate check directly (ex-post) in some cases; in other cases the company receives it and then quotes a subsidy-inclusive price (as well as the subsidy amount) to the customer. In the first case, consumers pay pre-subsidy prices. In the second case, consumers pay subsidy-inclusive prices, analogous to the case for TPO consumers. It is the first type of HO transactions in which CSI subsidies could be less than fully salient. ${ }^{28}$ However, as the rebate amount is always reported to the consumer at the time of purchase, the calculation method is transparent and easily verifiable, and the subsidy is large, it would be highly surprising if not all buyers and installers were aware of it. Thus, imperfect salience of CSI rebates is highly unlikely in both HO and TPO markets.

Another form of imperfect salience can arise from interactions between different subsidies. For example, regardless of whether the federal investment tax credit (ITC) and the CSI rebates themselves are salient to solar buyers, their interaction may not be (see Section 4). This issue does not apply to TPO; firms are certainly aware of the ITC and its interactions with the CSI, and consumers face fully salient, subsidy-inclusive prices. An HO customer, however, may overestimate the value of the CSI rebate; being unaware that the higher CSI rebate reduces the ITC amount, she may be unpleasantly surprised ex-post when learning from her tax return that the ITC is lower than expected. In terms of the discussion above, this is a case where the consumer would overreact to the CSI subsidy - the lack of salience of the subsidy interaction means that the subsidy itself is "too salient", so $\eta>1$ in Equation 9. As discussed in footnote 27, this reduces pass-through for HO and implies that if the interaction were more salient to HO customers, pass-through would increase.

Subsidy Manipulation.-Another factor that can explain differences in pass-through rates is a

\footnotetext{
${ }^{27}$ Although $\eta<1$ for most commodity taxes, $\eta>1$ can occur if consumers overestimate tax or subsidy rates, as appears to occur for opaque estate tax systems (Slemrod 2006). However, this case of the tax or subsidy being "super salient" would decrease pass-through even more to some amount less than pass-through under full optimization. Furthermore, $\eta<0$ would imply that consumers implicitly count on a tax actually being a subsidy, which we rule out as unreasonable.

${ }^{28}$ However, if subsidy-inclusive prices are indeed less salient for HO consumers than for TPO consumers, we would expect higher pass-through for HO systems. This is the opposite direction from what we find empirically in Section 4.
} 
differential ability of firms to evade taxes. We use Kopczuk et al. (2016)'s framework to argue that, in theory, over-shifting can occur in markets with a high degree of unobserved tax evasion. Analogously, subsidy over-shifting can also happen when companies are able to substantially manipulate or exaggerate the variables that determine the total subsidy so that they receive higher payments than the official subsidy amount observed by the econometrician. While we argue in this section that subsidy manipulation is nearly impossible in the context of the CSI rebate, ${ }^{29}$ we begin by discussing how it could theoretically explain pass-through that exceeds unity.

We consider the case of perfect competition and a per-unit tax $t$ (or a per-unit subsidy $s$ ) that is remitted by suppliers. The standard statutory incidence irrelevance result states that a tax levied on the demand side would leave pass-through and incidence unaffected. However, Kopczuk et al. (2016) show that allowing for differences in the ability to evade taxes between consumers and firms alters this well-known result. Pass-through then depends on remittance responsibility and the degree of tax evasion. Differentiating the equilibrium condition $D(p)=S(p-t)$ with respect to the tax rate yields the following pass-through expression for consumers:

$$
\frac{d p}{d t}=\frac{\varepsilon_{S}}{\varepsilon_{S}+\varepsilon_{D}}-\frac{\varepsilon_{N}}{\varepsilon_{S}+\varepsilon_{D}} \frac{E[e \mid t]}{q},
$$

where $q$ is total output, $e$ is the total amount of tax evasion, $\varepsilon_{N}$ is the price elasticity of the number of firms in equilibrium, and other variables are as previously defined.

We refer to Kopczuk et al. (2013) for the derivation but demonstrate here that their result implies the possibility of over-shifting. First, note that if there is no tax evasion $(e=0)$, the pass-through expression is identical to Equation 1. Next, when there is evasion $(e>0)$, there is a negative adjustment term applied to the standard pass-through expression. In other words, the tax-inclusive consumer price increases by less when firms (or consumers) can evade taxes. This is intuitive: firms and consumers together remit fewer taxes to the government than the official tax rate would suggest. This mitigates price changes. As econometricians, we interpret this as lower pass-through to consumers, even though firms end up paying lower taxes, too. ${ }^{30}$

The case of unobserved subsidy manipulation differs slightly. First, $d p / d s=-d p / d t$. Second, subsidy exaggeration in Kopczuk et al. (2016)'s setting goes in the opposite direction from tax evasion $e$ (i.e., $e$ is negative, as exaggeration is "negative evasion"): higher subsidies lead to more rents from manipulation, part of which benefits consumers in the form of lower subsidy-inclusive prices. Taken together, the effect of subsidy manipulation on $d p / d s$ is negative - the same official subsidy leads to a larger decrease in subsidy-inclusive consumer prices in the presence of manipulation. In

\footnotetext{
${ }^{29}$ Subsidy manipulation (or tax evasion) is conceivable in other markets or with other subsidies. For instance, in the U.S. solar market, there were allegations that the investment tax credit was subject to manipulation. We discuss below that this does not affect our pass-through estimates.

${ }^{30}$ Our analysis assumes that the firm has full remittance responsibility. However, if firms or consumers have differential abilities to evade taxes, the evasion effect on pass-through is larger when the remittance responsibility of the tax is shifted towards the side of the market with better abilities to evade. See Kopczuk et al. (2016) for a full treatment of this intuitive result.
} 
our regression framework, we would interpret that as higher pass-through. Intuitively, there is more subsidy money to be distributed between consumer and firm, which benefits consumers ("higher pass-through") even if the firm captures most of the manipulated subsidy increase.

Importantly, Equation 10 does not prevent the pass-through coefficient of the manipulated subsidy from exceeding 100 percent. In fact, if subsidy pass-through was close to 100 percent in a market without manipulation, even a modest amount of subsidy exaggeration could lead to overshifting. Note that this issue only arises if the actual (manipulated) subsidy received is unobserved and the econometrician only knows the statutory subsidy amount. If firms manipulate subsidies but we observe what they actually receive, the usual pass-through results from Section 2 apply and the subsidy exaggeration cannot explain over-shifting. We thus conclude that subsidy manipulation, if unobserved, increases estimated pass-through coefficients and can move them above 100 percent under special circumstances.

Although this sheds light on another potential explanation for over-shifting, the CSI rebate is almost certainly not subject to unobserved subsidy manipulation, ruling out this potential explanation for our over-shifting finding. The rebate amount is not determined based upon reported prices or imputed values but rather by the effective (i.e., location- and system-adjusted) system size. Manipulating such system features, which are transparent and easily verified through inspection, is extremely difficult or even impossible. ${ }^{31}$

For completeness, we mention that recent stories in the media report that third-party solar leasing and installation firms manipulated a different solar subsidy: the ITC (Greentech Media 2013). The ITC is 30 percent of the estimated value of solar systems, which some firms have allegedly inflated in order to reap larger ITCs. This manipulation was only possible for TPO systems, as there is no arm's length transaction price between the installer and the new owner (the leasing department of the same integrated company). For HO systems, the ITC was calculated based on the actual transaction price between the homeowner and the installation company, which is much harder to manipulate. These practices do not affect our estimates as we study the pass-through of CSI (not ITC) subsidies. ${ }^{32}$

Decreasing Marginal Costs.-Standard short-run analyses assume diminishing returns to inputs, or in other words, increasing marginal costs of production, and thus the supply elasticity $\varepsilon_{S}>0$. It follows immediately from Equation 1 that pass-through cannot exceed unity under this assumption in perfectly competitive markets (barring Giffen behavior). Nonetheless, over-shifting theoretically can occur if $\varepsilon_{S}<0$. However, this could only happen in industries with such strong returns to scale that the marginal cost function is decreasing in the short run. Also note that increasing returns to inputs often leads to an unstable equilibrium that requires government intervention (e.g., natural

\footnotetext{
${ }^{31}$ Furthermore, such manipulation would have been a very high-risk endeavor considering a proportion of projects were inspected to ensure accurate reporting, and thus the program was administered in a way that safeguarded against such behavior. An official administering the CSI program confirmed this.

${ }^{32}$ In addition, the value of the CSI rebate is independent of whether or not companies manipulated the ITC. As discussed in Appendix B.2, an extra dollar of CSI rebates reduces the value of the total ITC received by $\$ 0.30$, regardless of whether the ITC amount was overstated or not.
} 
monopoly).

Decreasing marginal costs are highly uncommon in general and are certainly not observed in the California solar market in the short run. Consideration of the TPO market's cost structure strongly suggests non-declining short-run marginal costs. The majority of the solar system cost is driven by "soft" costs such as labor, inventory and marketing. The TPO market is already characterized by a few dominant firms that employ sophisticated methods to take advantage of their scale in reducing such costs. Although one can imagine longer-run scale advantages from more efficient installation procedures or customer acquisition for small firms, it is difficult to imagine how increasing returns to labor and other installation cost inputs would have occurred in the short run for mature firms.

We are only aware of two empirical examples of markets with decreasing marginal costs: brick production (Bower 1964) and health insurance when adverse selection is present (Einav et al. 2010). It should be to no surprise that empirical evidence for decreasing short-run marginal costs is scant. The traditional micro model of a firm says that firms have increasing short-run marginal costs, based on the idea that in the short run there are fixed inputs and that variable inputs exhibit decreasing marginal products; in the long run, all factors can be changed. Of course, many industries with high fixed costs exhibit increasing marginal costs but decreasing average costs. The only models - as far as we know - that assumes decreasing short-run marginal costs are models of adverse selection.

Nominal Pricing Rigidities.-Conlon and Rao (2016) demonstrate that nominal rigidities in prices can rationalize pass-through over-shifting regardless of the shape of the underlying demand curve. While price changes that occur in coarse increments exist in specific contexts, such as in their empirical setting of distilled spirits markets, this is not the case in many markets and certainly not for solar systems.

\section{Demand Curvature and Over-Shifting}

Our empirical estimates in Section 4 show that the pass-through rate of solar subsidies in the residential sector has been high, with baseline pass-through for $\mathrm{HO}$ of 78 and 153 percent - substantially above 100 percent - for TPO. In Section 2, we discuss that such over-shifting is theoretically possible under imperfect competition when demand is sufficiently convex and indeed observed in various markets.

We now connect the theory of over-shifting — as elegantly laid out by Weyl and Fabinger (2013) with our solar market data. We aim to test if our data support a demand specification that is consistent with the over-shifting observed in the California solar market. In other words, we need to investigate if demand for residential solar systems is sufficiently convex to explain pass-through above unity in an imperfectly competitive market. To do this, we construct an empirical test of the over-shifting theory. While this may seem to be a natural subsequent inquiry in an empirical paper that finds more-than-complete pass-through, earlier papers that estimate pass-through rates have 
not explicitly connected the theory of pass-through under imperfect competition with an empirical test of demand convexity.

We begin by estimating demand for solar systems in the HO and TPO markets separately. In doing so, it is of crucial importance to specify a flexible enough demand function that allows for concave, convex or very convex demand. We therefore take the approach of estimating quadratic demand specifications for HO and TPO systems, computing the range of prices (if any) over which Seade (1985) and Weyl and Fabinger (2013) would predict over-shifting, both for HO and TPO, and testing whether our pass-through estimates are consistent with these price ranges.

As it turns out, this analysis is complicated by the fact that the relevant convexity parameter $\varepsilon_{m s}$ from the pass-through theory (defined below Equation 2)-and therefore the range of prices over which one would expect over-shifting in a market characterized by imperfect competitionis sensitive to the parameters of a flexibly estimated demand specification. Therefore, the main contribution of this exercise is not to provide precise price ranges over which over-shifting occurs in the solar markets studied here but rather to illustrate how the theory of over-shifting can be empirically tested with a standard demand estimation. We provide - to the best of our knowledgethe first empirical test of consistency between over-shifting and demand curvature. As such, we show that empiricists can directly test pass-through theory to lend additional credibility to empirical estimates of pass-through rates that exceed 100 percent by taking demand curvature seriously.

The power of this demand curvature test to support over-shifting depends on the availability of sufficiently rich data. We cannot emphasize enough, however, that our demand estimates are noisy, so our conclusions about the exact price range over which we predict over-shifting under imperfect competition need to remain modest. We consider the analysis below to be a compromise between a full-fledged test based on a complete and precise demand estimation and an extensive numerical example. Nonetheless, the exercise illustrates the mechanics of how one could implement such a test when sufficiently rich data is available.

\subsection{Demand Estimation}

\subsubsection{Econometric Framework}

We estimate a demand equation that flexibly allows for different degrees of convexity or concavity. We choose the simplest form: demand for solar systems as a quadratic function of their prices. The coefficient on the squared price term directly measures convexity. The usual simultaneity bias justifies an instrumental variables estimator. We estimate the following equation by 2SLS with data aggregated at the zip code by year level:

$$
q_{i t}=\beta_{1} p_{i t}+\beta_{2} p_{i t}^{2}+\mathbf{X}_{i t} \theta+\delta_{j}+\tau_{t}+\varepsilon_{i t},
$$

where $i$ indicates zip code and $t$ denotes year. The dependent variable $q_{i t}$ is the installation rate defined as the number of residential solar systems installed in a particular zip code and year per 
1,000 inhabitants. We normalize by population given the vast differences in population across zip codes in California. On the right-hand side, $p_{i t}$ is the post-incentive price per watt, $\delta_{j}$ are county fixed effects, $\tau_{t}$ are year fixed effects, and $\varepsilon_{i t}$ is an error term. $\mathbf{X}_{i t}$ includes the same demographic controls that we use in the pass-through regressions in Section 4 as well as electricity rates.

Although our model includes year fixed effects, electricity rates - which affect demand for solar because higher electricity prices increase electricity bill savings realized from solar adoption - change within year. Electricity prices in California follow a tiered rate structure, where electricity rates increase with household consumption. We follow Hughes and Podolefsky (2015) and include each IOU's rates for the three highest tiers.

We identify our demand parameters based on zip code and time variation in the solar installation rate and price after controlling for observables and instrumenting for the price. We instrument for $p_{i t}$ and $p_{i t}^{2}$ using a set of supply shifters. We follow Gillingham and Tsvetanov (2017) in using the rebate and its square (in dollars per Watt; as defined and used in the pass-through regressions from Section 4) as well as the county-level electrician/wiring wage rate and its square. The latter is a proxy for solar installer wages.

Both CSI rebates and wages are credible instruments. Electricians' wages act as an exogenous cost shifter which plausibly affects demand only through its effect on the price of the solar system. The sharp variation in rebate levels from the step changes described in Section 3.1 provides a source of exogenous solar panel cost variation. As firms earn such rebates, their supply curve shifts downwards by the incentive amount. Hence, rebates can be used as cost shifters that can aid in identifying demand. ${ }^{33}$

Any instrumental variables estimator assumes an exclusion restriction - ours is that any omitted variables that end up in the error term are uncorrelated with our instruments (rebates and wages). The inclusion of year and county fixed effects flexibly account for time trends in installation rates that are common across counties, as well as time-invariant differences across counties. These absorb some complications from swings in macroeconomic conditions during our sample period. However, the CSI program might have had general equilibrium effects on electricians' wages through increased demand for electricians. Also, there might be omitted demand shifters, such as changes in tastes for the visual aspects of solar panels or preferences towards being less reliant on the incumbent utility company, that exhibit different trends in different zip codes. Such omitted variables could introduce bias insofar as they correlate with our instruments. Through the exclusion restriction, we maintain the assumption that the impact of such variables is negligible.

\subsubsection{Data}

The underlying dataset is the same as in the pass-through analysis (see Section 4 for details), except that we add to each installation the corresponding tiered electricity rates (based on location and

\footnotetext{
${ }^{33}$ This description applies directly to the TPO market, where firms receive the CSI rebates. In the HO market, the rebates are sometimes paid to the firm. In other cases, they are paid to the consumer. In our setting where we model post-incentive prices for consumers, and assuming the standard statutory incidence irrelevance result, the latter case is analogous to the firm's supply curve shifting down while the demand curve remains fixed.
} 
date at which the household applied for the CSI rebate) and county-level data on electricity/wiring wages from the U.S. Bureau of Labor Statistics. Additionally, we keep all TPO installations, not just those whose contracts have been transcribed. We then aggregate the data to create a balanced panel. Statistical power forces us to trade off temporal and cross-sectional price variation, so we follow others in the literature by using annual installations but small geographic regions due to the likely heterogeneity across regions in environmental preferences and other characteristics (Gillingham and Tsvetanov 2017). We aggregate to the zip code by year level, separately for HO and TPO systems. ${ }^{34}$ This leaves some zip code-year observations with missing data for some variables, mostly where there are zero installations in a given zip code-year or where there are TPO installations but we do not have TPO contract prices (because our pricing data covers a relatively limited fraction of TPO contracts). We interpolate missing data using observations from surrounding areas, as described in Appendix B.1. The final dataset contains data on installations rates, contract types, prices and control variables for 1,958 zip codes for each of the years 20102013. Our main specifications exclude zip codes with less than 100 inhabitants, as these are mostly non-representative commercial districts or remote areas. See Appendix B.1 for more details on the data for the demand regressions.

Appendix Table B.1 contains summary statistics of the data used for the demand estimations. Demand rates for HO and TPO are not statistically different. Differences for HO and TPO rebates, post-incentive prices, and system size are statistically different in some cases but relatively modest in terms of economic magnitudes. There are no significant demographic differences that stand out.

\subsubsection{Results}

Table 6 shows the results of the demand estimation. We provide OLS results in columns 1 and 2 and IV estimates in columns 3 and 4 . Across all specifications, we find that demand is convex, as indicated by the positive coefficients on the squared price term. For both HO and TPO, the IV estimates pass the weak instruments test (as indicated by the two Sanderson-Windmeijer Fstatistics), but they are imprecisely estimated, not statistically significant, and they differ from the OLS estimates. Still, IV is the theoretically correct way to estimate demand. While acknowledging the limitations from large standard errors, we continue to illustrate the implications of our estimated demand parameters for over-shifting.

When translating the parameter estimates from the IV specifications in Table 6 to price elasticities, we find that, at the average price in our sample of $\$ 3.70$ per watt, the demand elasticity is -0.85 for $\mathrm{HO}$ and -0.42 for TPO. ${ }^{35}$ Demand becomes more elastic as prices decrease. The relative inelasticity of demand for TPO versus HO systems suggests one reason why pass-through rates are

\footnotetext{
${ }^{34}$ We caveat that aggregating data across geography and/or time masks responses to price changes within, e.g., years or zip codes - an issue that is common to many demand estimations.

${ }^{35}$ Our estimates are generally in the same range as others in the literature. Gillingham and Tsvetanov (2017) find a price elasticity of demand for solar PV systems of -1.76 in Connecticut. However, using California data, Hughes and Podolefsky (2015) estimate a "rebate elasticity" of approximately -1.2 , which is most usefully comparable to our estimate for HO systems. No other studies have estimated elasticities for the TPO market.
} 
Table 6: Demand Estimates for HO vs. TPO Systems

\begin{tabular}{|c|c|c|c|c|}
\hline & $(1)$ & $(2)$ & $(3)$ & $(4)$ \\
\hline & \multicolumn{2}{|c|}{ OLS } & \multicolumn{2}{|c|}{ IV } \\
\hline & $\mathrm{HO}$ & $\mathrm{TPO}$ & $\mathrm{HO}$ & TPO \\
\hline Price & $\begin{array}{c}-0.261^{* * *} \\
(0.082)\end{array}$ & $\begin{array}{c}-0.183^{*} \\
(0.094)\end{array}$ & $\begin{array}{c}-0.534 \\
(0.898)\end{array}$ & $\begin{array}{c}-1.929 \\
(2.249)\end{array}$ \\
\hline Price $^{2}$ & $\begin{array}{c}0.026^{* * *} \\
(0.008)\end{array}$ & $\begin{array}{c}0.027^{* *} \\
(0.012)\end{array}$ & $\begin{array}{c}0.053 \\
(0.099)\end{array}$ & $\begin{array}{c}0.241 \\
(0.289)\end{array}$ \\
\hline $\begin{array}{l}\text { Mean of dependent variable } \\
\text { First stage F-statistic (price) } \\
\text { p-value (price) } \\
\text { First stage F-statistic }\left(\text { price }^{2}\right) \\
\text { p-value }\left(\text { price }^{2}\right)\end{array}$ & 0.461 & 0.518 & $\begin{array}{l}0.461 \\
10.40 \\
0.000 \\
10.16 \\
0.000 \\
\end{array}$ & $\begin{array}{l}0.518 \\
18.86 \\
0.000 \\
18.35 \\
0.000 \\
\end{array}$ \\
\hline Controls & $\mathrm{x}$ & $\mathrm{x}$ & $\mathrm{x}$ & $\mathrm{x}$ \\
\hline County FE & $\mathrm{x}$ & $\mathrm{x}$ & $\mathrm{x}$ & $\mathrm{x}$ \\
\hline Year FE & $\mathrm{x}$ & $\mathrm{x}$ & $\mathrm{x}$ & $\mathrm{x}$ \\
\hline Number of observations & 5,196 & 5,196 & 5,196 & 5,196 \\
\hline
\end{tabular}

Notes: Dependent variable is the solar system installation rate. Observations are at the zip code by year level for zip codes with 100 inhabitants or more. Data cover systems installed in California for consumers who applied for the CSI rebate during the period 2010-Q2 2013. Controls includes the same demographics that we use in Table 2, as well as tiered electricity rates. A 7 percent discount rate is assumed for the net present cost and MACRS calculations. IV estimates in columns 3 and 4 instrument for (squared) price using the (squared) CSI rebate and the (squared) county-level electrician/wiring wage rate. F-statistic is the Sanderson-Windmeijer multivariate F-test of excluded instruments (for each of the first-stage regressions). Standard errors clustered by zip code. Asterisks denote ${ }^{*} p<0.10,{ }^{* *} p<0.05,{ }^{* * *} p<0.01$.

higher for TPO, yet this alone cannot explain over-shifting. ${ }^{36}$

Appendix Table C.3 shows how the demand parameters vary with alternative sample selection or variable construction rules. First, we define the solar installation rate based on the number of people who live in houses they own instead of total population. Second, we include the lowpopulation zip codes. The estimates are similar to those in Table 6. Finally, we discuss the IV results when only a subset of instruments is used. The IV estimates for $\mathrm{HO}$ are broadly similar to those in Table 6, but the IV results for TPO are very noisy. We therefore prefer the estimates in Table 6 .

\subsection{Implications for Over-Shifting}

Theory predicts that, under monopoly and many other forms of imperfect competition, over-shifting occurs when demand is sufficiently convex, i.e. $1 / \varepsilon_{m s}<0$, as summarized by Equation 5 . Having estimated separate demand functions for HO and TPO consumers, we now calculate $1 / \varepsilon_{m s}$ using our estimated demand coefficients along different points of these demand curves (see Appendix C.3 for details).

Figure 5 shows the inverse demand curves for HO and TPO. The shaded areas indicate the

\footnotetext{
${ }^{36}$ Note that our market demand elasticities at the average price of $\$ 3.70$ are greater than -1 . A firm with market power will price on the elastic portion of its residual demand curve, which is more elastic than the market demand curve. Hence, our inelastic market demand estimates do not contradict optimal pricing.
} 
Figure 5: Demand Curve for Solar Systems

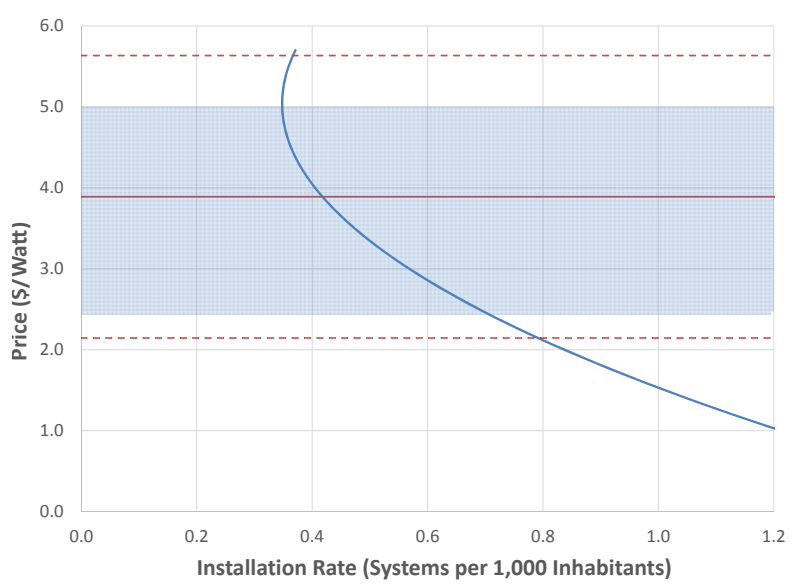

(a) Host-Owned Systems

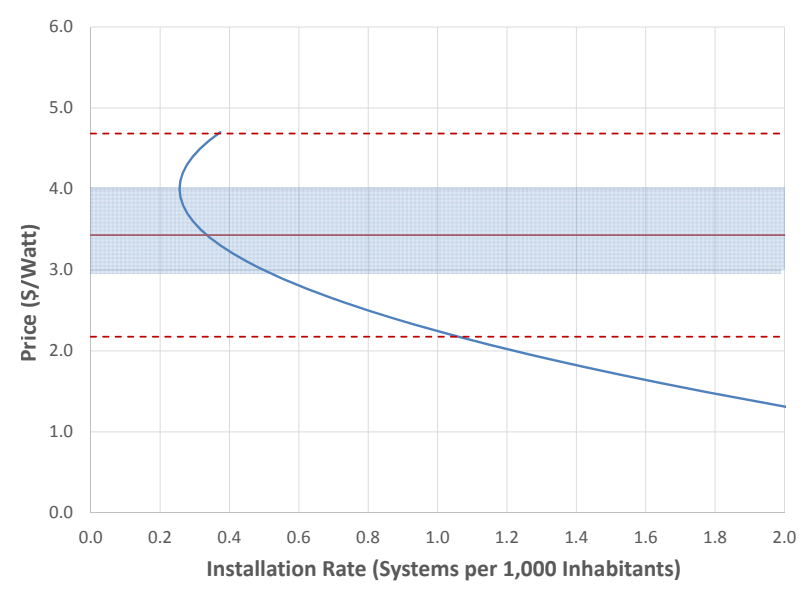

(b) Third-Party Owned Systems

Note: Figure plots the IV specifications in columns 3 and 4 in Table 6. Solid red lines indicate mean price level. Dotted red lines indicate mean price $-1.96 /+1.96$ times the standard deviation. Shaded regions indicate the price range over which demand is log-convex.

price range over which the demand curves are log-convex. The solid red line shows the mean price; the dotted red lines indicate the "95 percent range" for prices. As the demand curve is a quadratic in price, the inverse demand curve can bend backward for high prices if there are high-price and high-installation areas. We can conclude from these graphs that there is a sizeable price range over which demand is log-convex; for both $\mathrm{HO}$ and TPO. This provides suggestive evidence that the solar market is indeed a candidate for over-shifting when market power is present, over at least some range of prices that are reasonable for this market and time period.

As discussed above, we include this analysis to demonstrate how flexibly estimating demand can help provide further evidence to support empirical estimates of over-shifting. While the curvature of demand in the residential solar sector appears consistent with the possibility of over-shifting, we also remind the reader that our demand equations are imprecisely estimated and the convexity ranges are sensitive to demand parameters. Nonetheless, this procedure can be applied more broadly to provide supporting evidence for empirical findings of over-shifting, which can in turn be used to argue for the presence of market power if alternative explanations can be convincingly ruled out.

\section{Conclusion}

Pass-through is an important tool of economic analysis as it can reveal important characteristics about supply, demand, or market power. In this paper, we demonstrate how an empirical finding of pass-through over-shifting can serve as a simple test for the existence of market power. We estimate pass-through in an important empirical setting: the market for solar systems in California under the California Solar Initiative, the largest state solar rebate program to date in the United States. We allow pass-through to differ between buyers and lessees of solar systems. We find that pass- 
through is remarkably high in both markets and over-shifts for lessees. Pass-through to consumers who purchase their solar panels is about 78 cents for every dollar increase in subsidies. For leases, a $\$ 1$ increase in subsidies translates to a decrease in solar system prices of $\$ 1.53$. These estimates do not support popular claims that solar companies appropriate most of the subsidies. However, at the same time, we provide evidence that the TPO solar market is imperfectly competitive, which implies that consumer surplus is lower than in a competitive market.

The substantial over-shifting in the leasing market can be explained by imperfect competition combined with "sufficiently convex" demand, but there exist other conditions - including but not limited to Giffen behavior, decreasing marginal costs, and unobserved subsidy manipulation - under which over-shifting can occur. We formalize pass-through over-shifting as an under-utilized test for market power by outlining and ruling out these alternative explanations. We conclude that, in the setting of the California solar market, over-shifting can only be rationalized by imperfect competition and sufficiently convex demand. We reinforce this conclusion with an empirical test of demand curvature for solar systems, which indeed suggests sufficiently convex demand. While this more-than-complete pass-through may seem surprising, over-shifting has been found in many markets.

This paper is the first to estimate pass-through of green energy subsidies in a third-party market and to contrast pass-through for buyers and lessees of (virtually) the same product. Our results shed light on how the benefits of such subsidies accrue across different types of consumers and firms, which should be of interest to policy makers. The substantial difference in pass-through is not only interesting to highlight that HO and TPO systems cannot be treated as a single market for solar panels, but also because it suggests that buy and lease markets could differ in other contexts, such as automobiles, planes, and computers. Consequently, future research could focus on how tax incidence differs across the buy and lease segments of such markets.

Most importantly, we argue that estimating pass-through and finding that it over-shifts can serve as a powerful diagnostic for detecting market power that can be applied beyond the solar market. The appeal of this approach lies in the simplicity of a pass-through estimation that usually imposes only limited data and computational demands. Economists and competition authorities therefore should be particularly interested in industries characterized by over-shifting, as this is often a strong signal that they are at risk of imperfect competition and may require further investigation. Of course, the absence of pass-through over-shifting does not imply that the market is perfectly competitive. 


\section{References}

Anderson, S.P., A. de Palma, and B. Kreider, "Tax Incidence in Differentiated Product Oligopoly," Journal of Public Economics, 2001, 81, 173-192.

Barnett, P.G., T.E. Keeler, and H. Teh-Wei, "Oligopoly Structure and the Incidence of Cigarette Excise Taxes," Journal of Public Economics, 1995, 57 (3), 457-470.

Barzel, Y., "An Alternative Approach to the Analysis of Taxation," Journal of Political Economy, 1976, 84 (6), 1177-1197.

Beresteanu, A. and S. Li, "Gasoline Prices, Government Support, and the Demand for Hybrid Vehicles in the U.S.," International Economic Review, 2011, 52 (1), 161-182.

Besley, T.J. and H.S. Rosen, "Sales Taxes and Prices: An Empirical Analysis," National Tax Journal, 1999, 20 (3), 235-249.

Bollinger, B. and K. Gillingham, "Learning-by-Doing in Solar Photovoltaic Installations," 2014. Working Paper.

Boomhower, J. and L. Davis, "A Credible Approach for Measuring Inframarginal Participation in Energy Efficiency Programs," Journal of Public Economics, 2014, 113, 67-79.

Borenstein, S., "Private Net Benefits of Residential Solar PV: The Role of Electricity Tariffs, Tax Incentives, and Rebates," Journal of the Association of Environmental and Resource Economists, 2017, 4 (S1), S85 - S122.

- and L. Davis, "The Distributional Effects of US Clean Energy Tax Credits," Tax Policy and the Economy, 2016, 30 (1), 191-234.

Bower, R., "Decreasing Marginal Cost in Brick Production," Journal of Industrial Economics, 1964, 13 (1), 1-10.

Bulow, J.I. and P. Pfleiderer, "A Note on the Effect of Cost Changes on Prices," Journal of Political Economy, 1983, 91 (1), 182-185.

Burr, C., "Subsidies, Tariffs and Investments in the Solar Power Market," 2014. Working Paper.

Busse, M.R., C.R. Knittel, J. Silva-Risso, and F. Zettelmeyer, "Did "Cash for Clunkers" Deliver? The Consumer Effects of the Car Allowance Rebate System," 2012. Working Paper, CEEPR WP 2013-009.

_ , J. Silva-Risso, and F. Zettelmeyer, "\$1,000 Cash Back: The Pass-Through of Auto Manufacturer Promotions," American Economic Review, 2006, 96 (4), 1253-1270.

Chetty, R., A. Looney, and K. Kroft, "Salience and Taxation: Theory and Evidence," American Economic Review, 2009, 99 (4), 1145-1177.

Conlon, C. and N. Rao, "Discrete Prices and the Incidence and Efficiency of Excise Taxes," 2016. Working Paper.

Delipalla, S. and M. Keen, "The Comparison Between Ad Valorem and Specific Taxation Under Imperfect Competition," Journal of Public Economics, 1992, 49 (3), 351-367. 
- and O. O'Donnell, "Estimating Tax Incidence, Market Power and Market Conduct: The European Cigarette Industry," International Journal of Industrial Organization, 2001, 19 (6), 885-908.

Dong, C.G., R.H. Wiser, and V. Rai, "Incentive Pass-through for Residential Solar Systems in California," 2016. Lawrence Berkeley National Laboratory.

Einav, L., A. Finkelstein, and M.R. Cullen, "Estimating Welfare in Insurance Markets Using Variation in Prices," The Quarterly Journal of Economics, 2010, 125 (3), 877-921.

Fabra, N. and M. Reguant, "Pass-Through of Emissions Costs in Electricity Markets," American Economic Review, 2014, 104 (9), 2872-2899.

Ganapati, S., J. Shapiro, and R. Walker, "The Incidence of Carbon Taxes in U.S. Manufacturing: Lessons from Energy Cost Pass-Through," 2016. NBER Working Paper No. 22281.

Gillingham, K. and T. Tsvetanov, "Hurdles and Steps: Estimating Demand for Solar Photovoltaics," 2017. Working Paper.

_, H. Deng, R. Wiser, N. Darghouth, G. Nemet, G. Barbose, V. Rai, and C. Dong, "Deconstructing Solar Photovoltaic Pricing: The Role of Market Structure, Technology, and Policy," The Energy Journal, 2016, 37 (3).

Goldberg, P. and R. Hellerstein, "A Structural Approach to Identifying the Sources of LocalCurrency Price Stability," Review of Economic Studies, 2013, 80 (1), 175-210.

Greentech Media, "Why Treasury Is Investigating SolarCity and Solar Third-Party Funds," December 192013.

_ , "Deep Politics, Dark Money and Fraud Join the Solar Party," June 202016.

Gulati, S., C. McAusland, and J. Sallee, "Tax Incidence with Endogenous Quality and Costly Bargaining: Theory and Evidence from Hybrid Vehicle Subsidies," Journal of Public Economics, 2017, 155, 93-107.

Hughes, J. and M. Podolefsky, "Getting Green with Solar Subsidies: Evidence from the California Solar Initiative," Journal of the Association of Environmental and Resource Economists, 2015, 2 (2), 235-275.

International Energy Agency, World Energy Outlook 2016, IEA Publications: Paris, France, 2016.

Ito, K., "Asymmetric Incentives in Subsidies: Evidence from a Large-Scale Electricity Rebate Program," American Economic Review, 2015, 7 (3), 209-37.

Jenkin, F., "On the Principles Which Regulate the Incidence of Taxes," Proceedings of the Royal Society of Edinburgh, 1872, 7, 618-631.

Jensen, R.T. and N.H. Miller, "Giffen Behavior and Subsistence Consumption," American Economic Review, 2008, 98 (4), 1553-1577.

Jordan, D.C. and S.R. Kurtz, "Photovoltaic Degradation Rates - an Analytical Review," Progress in Photovoltaics, 2013, 21 (1), 12-29. 
Kalpin, M.C., J. Jerome, and P. Bernhardt, "FTC Workshop Examines Competition and Consumer Protection Issues in Rooftop Solar Industry," July 12016.

Katz, M.L. and H.S. Rosen, "Tax Analysis in an Oligopoly Model," Public Finance Quarterly, 1985, 13, 3-19.

Kaul, A., G. Pfeifer, and S. Witte, "The Incidence of Cash for Clunkers: Evidence from the 2009 Car Scrappage Scheme in Germany," International Tax and Public Finance, 2016, 23 (6), $1093-1125$.

Kenkel, D.S., "Are Alcohol Tax Hikes Fully Passed Through to Prices? Evidence from Alaska," American Economic Review Papers and Proceedings, 2005, 95 (2), 273-277.

Kirwan, B., "The Incidence of U.S. Agricultural Subsidies on Farmland Rental Rates," Journal of Political Economy, 2009, 117 (1), 138-164.

Kopczuk, W., J. Marion, E. Muehlegger, and J. Slemrod, "Do the Laws of Tax Incidence Hold? Point of Collection and the Pass-Through of State Diesel Taxes," 2013. NBER Working Paper 19410.

${ }_{-}, \ldots, \ldots$, and $\_,$"Does Tax-Collection Invariance Hold? Evasion and the Pass-through of State Diesel Taxes," American Economic Journal: Economic Policy, 2016, 8 (2), 251-286.

Marion, J. and E. Muehlegger, "Fuel Tax Incidence and Supply Conditions," Journal of Public Economics, 2011, 95 (9), 1202-1212.

McIntosh, R. and J. Mandel, "Why Solar Installers Are Becoming Vertically Integrated," July 19 2014. CleanTechnica.

Nafari, K., "Behavioral Responses to Tax Kinks in the Rental Housing Market: Evidence from Iran," 2017. Working Paper.

Nakamura, E. and D. Zerom, "Accounting of Incomplete Pass-Through," Review of Economic Studies, 2010, 77 (3), 1192-1230.

Nemet, G., E. O'Shaughnessy, R. Wiser, N. Darghouth, G. Barbose, K. Gillingham, and V. Rai, "Characteristics of Low-Priced Solar PV Systems in the U.S.," Applied Energy, 2017, 187, 501-513.

Pless, J., R. Langheim, C. Machak, H. Hellow, and B. Sigrin, "The Price-Concentration Relationship in Early Residential Solar Third-Party Markets," 2017. National Renewable Energy Laboratory NREL/TP-6A20-66784.

Podolefsky, M., "Tax Evasion and Subsidy Pass-Through under the Solar Investment Tax Credit," 2013. University of Colorado at Boulder, Working Paper No. 13-05.

Ritz, R., "The Simple Economics of Asymmetric Cost Pass-Through," 2015. Cambridge Working Paper in Economics, EPRG Working Paper 1511.

Sallee, J., "The Surprising Incidence of Tax Credits for the Toyota Prius," American Economic Journal: Economic Policy, 2011, 3 (2), 189-219.

Seade, J., "Profitable Cost Increases and the Shifting of Taxation: Equilibrium Responses of Markets in Oligopoly," 1985. Manuscript. 
Slemrod, J., "The Role of Misconceptions in Support for Regressive Tax Reform," National Tax Journal, 2006, 59 (1), 57-75.

Stern, N., "The Effects of Taxation, Price Control and Government Contracts in Oligopoly and Monopolistic Competition," Journal of Public Economics, 1987, 32 (2), 133-158.

Stolper, S., "Who Bears the Burden of Energy Taxes? The Role of Local Pass-Through," 2016. Working Paper.

van Benthem, A.A., K. Gillingham, and J. Sweeney, "Learning-by-Doing and the Optimal Solar Policy in California," The Energy Journal, 2008, 29 (3), 131-151.

Watchdog Wire, "How Solar Leases Scam the Homeowner and Solar Contractors Keep the Subsidies," December 192014.

West, S., "Distributional Effects of Alternative Vehicle Pollution Control Policies," Journal of Public Economics, 2004, 88 (3-4), 735-757.

Weyl, G. and M. Fabinger, "Pass-Through as an Economic Tool: Principles of Incidence under Imperfect Competition," Journal of Political Economy, 2013, 121 (3), 528-583.

Young, D.J. and A. Bielinska-Kwapisz, "Alcohol Taxes and Beverage Prices," National Tax Journal, 2002, 55 (1), 57-73. 


\section{Appendices}

\section{A Theory and Proofs}

\section{A.1 Pass-Through in the Presence of Market Power}

We provide the equation for pass-through under monopoly in Equation 2 of the main text. Drawing directly from Weyl and Fabinger (2013), we derive this equation here by considering the monopolist's optimization problem and solving for the pass-through rate $\rho$, or the rate at which the price, $p$, changes with marginal cost, $m c$. The monopolist's revenues are $p(q) q$ with marginal revenue $m r(q)=p(q)+p^{\prime}(q) q$ and marginal cost $m c(q)=c^{\prime}(q)$. The monopolist maximizes profits by choosing quantity such that $m r(q)=m c(q)+t$, where $t$ is a per-unit tax on producers. Thus,

$$
\begin{aligned}
m r^{\prime} \frac{d q}{d t} & =m c^{\prime} \frac{d q}{d t}+1 \Rightarrow \frac{d q}{d t}=\frac{1}{m r^{\prime}-m c^{\prime}} \\
& \Rightarrow \rho=\frac{d p}{d t}=p^{\prime} \frac{d q}{d t}=\frac{p^{\prime}}{m r^{\prime}-m c^{\prime}} .
\end{aligned}
$$

Marginal revenue, $m r=p+p^{\prime} q$, is made up of two terms, the price $p$ and the negative of the marginal consumer surplus $m s=-p^{\prime} q$, which is what consumers earn when quantity expands. As such, we can write

$$
\rho=\frac{1}{\frac{p^{\prime}-m s^{\prime}}{p^{\prime}}-\frac{m c^{\prime}}{p^{\prime}}}=\frac{1}{1+\frac{\varepsilon_{D}}{\varepsilon_{m s}} \frac{m s}{p}+\frac{\varepsilon_{D}}{\varepsilon_{S}} \frac{m c}{p}},
$$

where $\varepsilon_{D} \equiv-D^{\prime} p / q$ is the elasticity of demand, $\varepsilon_{S} \equiv S^{\prime} p / q$ is elasticity of supply, and the elasticity of the inverse marginal surplus function is $\varepsilon_{m s}=m s /\left(m s^{\prime} q\right)$. We can further simplify the passthrough equation using

$$
\frac{m s}{p}=-\frac{p^{\prime} q}{p}=\frac{1}{\varepsilon_{D}}
$$

and Lerner's (1934) rule

$$
\frac{p-m c}{p}=\frac{1}{\varepsilon_{D}} \Rightarrow \frac{m c}{p}=\frac{\varepsilon_{D}-1}{\varepsilon_{D}}
$$

to yield

$$
\rho=\frac{1}{1+\frac{\varepsilon_{D}-1}{\varepsilon_{S}}+\frac{1}{\varepsilon_{m s}}} .
$$


As discussed in the main text of the paper, there are two key differences between pass-through under perfect and imperfect competition. First, $\varepsilon_{D}-1$ has replaced $\varepsilon_{D}$. Second, more importantly, there is the new term containing the inverse elasticity of marginal surplus, $\varepsilon_{m s}$, which measures the curvature of (the logarithm of) demand. In other words, pass-through under imperfect competition is not just determined by the elasticity of supply and demand but also the curvature of demand.

As Weyl and Fabinger (2013) discuss more extensively, the inverse elasticity of marginal surplus, $\varepsilon_{m s}$, measures the curvature of the logarithm of demand. Recall $m s=-p^{\prime} q$ and $D \equiv D(p)$, so $D^{\prime}=d D / d p=d q / d p$, and thus

$$
(\log D)^{\prime}=\frac{D^{\prime}}{D}=\frac{\frac{d q}{d p}}{q}=\frac{1}{\frac{d p}{d q} q}=\frac{1}{p^{\prime} q}=-\frac{1}{m s}
$$

and

$$
(\log D)^{\prime \prime}=\frac{m s^{\prime}}{m s^{2}} \frac{1}{p^{\prime}}=-\frac{1}{\varepsilon_{m s}} \frac{1}{m s}\left(-\frac{1}{p^{\prime} q}\right)=-\frac{1}{\varepsilon_{m s}} \frac{1}{m s^{2}} .
$$

Hence, demand is log-concave when $1 / \varepsilon_{m s}>0$ and log-convex when $1 / \varepsilon_{m s}<0$. Another threshold of interest is that $1 / \varepsilon_{m s}>1$ for concave demand and $1 / \varepsilon_{m s}<1$ for convex demand. This is because the inverse elasticity of marginal surplus is

$$
\frac{1}{\varepsilon_{m s}}=\frac{m s^{\prime} q}{m s}=\frac{\left(p^{\prime \prime} q+p^{\prime}\right) q}{p^{\prime} q}=1+\frac{p^{\prime \prime} q}{p^{\prime}}
$$

and given that $q>0>p^{\prime}$, the second term $p^{\prime \prime} q / p^{\prime}$ is positive if $p^{\prime \prime}<0$ and $1 / \varepsilon_{m s}>1$, and vice versa.

One can follow similar steps to derive pass-through for the more general case of symmetric, imperfect competition, which Weyl and Fabinger (2013) show is

$$
\rho=\frac{1}{1+\frac{\theta}{\varepsilon_{\theta}}+\frac{\varepsilon_{D}-\theta}{\varepsilon_{S}}+\frac{\theta}{\varepsilon_{m s}}},
$$

where $\theta$ is a conduct parameter between zero for perfect competition and one for a pure monopoly. Analogous to the case of the monopoly with constant marginal costs (infinite $\varepsilon_{S}$ ), pass-through exceeds unity if and only if $\varepsilon_{m s}$ is negative since $1 / \varepsilon_{\theta}=0$ for many standard models of imperfect competition, such as Cournot. 


\section{A.2 Second Order and Stability Conditions}

We primarily focus on the threshold for pass-through over-shifting to occur. For completeness, we note that one may also wish to check the range of $\varepsilon_{m s}$ values against the second order and stability conditions for the firm's profit maximization problem to ensure consistency with stable symmetric market equilibrium. The second order condition states that the second derivative of the profit function is non-positive. Stability implies that equilibrium is restored when disturbing an initial equilibrium by changing each firm's output by any specified amount $\delta$.

Seade (1985) derives these conditions. In our notation, the second order condition under symmetry can be written as

$$
\varepsilon_{m s}<\frac{1}{1-2 n}
$$

where $n$ is the number of firms in the market. The stability condition that is necessary and sufficient under symmetry can be written as

$$
\varepsilon_{m s}<-\frac{1}{n}
$$

This implies that a stable equilibrium requires stricter conditions than $\varepsilon_{m s}<0$ on the range of prices over which over-shifting occurs.

\section{B Data}

\section{B.1 Additional Details on Data Preparation}

\section{B.1.1 Data for the Pass-Through Regressions}

The CSI dataset that we start with is the public "working dataset" file posted on the CSI website on June 24, 2015. ${ }^{37}$ We took a few other steps to prepare the data in addition to what we describe in Section 3. First, through the National Renewable Energy Laboratory (NREL), we obtained a non-disclosure agreement with the California Public Utilities Commission to gain access to and transcribe detailed terms from a proprietary dataset of residential third-party solar contracts in California. Obtaining usable price data from these required our manual transcription because they lacked consistency across contract type and company, and they were often hand-written. As such, we stratified the data by quarter and drew a random sample of 200 observations per quarter of all residential TPO projects with a CSI completion date. Not all contracts that we sampled contained enough data to construct a net present cost (NPC), leaving us with 1,346 contracts in total with usable data.

\footnotetext{
${ }^{37}$ The CSI data are available online at https://www.californiasolarstatistics.ca.gov/data_downloads/
} 
We impose a number of sample selection rules on the full dataset. We drop a small number of observations that are most likely data errors. These include two systems with prices above $\$ 20 /$ watt and seven systems with prices below $\$ 0.50 /$ watt. Next, we limit the data to installations with status listed as "installed" or "pending" because if "cancelled" the recorded contract terms likely do not reflect market conditions. We also drop 13 systems for which the listed incentive amount exceeds the total reported system cost, which is infeasible and thus data entry error.

We keep only residential systems and those who participate in the Expected Performance Based Buydown (EPBB) program, which was the upfront lump-sum rebate option offered by CSI. While residential customers could use a Performance Based Incentive (PBI) instead, more than 99\% of residential consumers opted for EPBB. We also drop observations filed under the Multifamily Affordable Solar Housing (MASH) program as decision-making for multi-family housing is fundamentally different from individual households. Another non-representative class of contracts that we drop is those with "GRID Alternatives", a nonprofit that brings together community partners, volunteers, and installers to implement projects for low-income families.

We restrict our dataset to systems up to 10 kilowatts, as larger systems are highly unlikely to have a residential-only purpose. Almost all residential solar electric systems require between 50 square feet and 1,000 square feet, and a general rule that is often applied is that 100 square feet of solar panels will generate 1 kilowatt of electricity (Hois, 2016). For systems above 10 kilowatts, there is a high risk of data errors and confusion with small commercial systems, which are outside the scope of the market we are interested in studying.

We reduce dimensionality in the installer fixed effects by grouping together firms with few installations. The smallest firms that together install $5 \%$ of solar systems are combined into one category. We apply the same rule for manufacturer and module model fixed effects.

We extend the dataset by merging in demographics at the census tract level using demographics from the American Community Survey. For that purpose, researchers at NREL geocoded the CSI data with latitudes and longitudes from address locations. We merged this with the post-incentive price data as well as the CSI data.

Finally, we end our sample at the end of June 2013. At that time, the CSI program was nearly exhausted. While Southern California Edison (SCE) and San Diego Gas \& Electric (SDG\&E) territories still provided CSI rebates at the lowest level, Pacific Gas \& Electric (PG\&E) ran out of CSI funding at the end of April 2013.

\section{B.1.2 Data for the Demand Regressions}

The dataset we use for the demand regressions is similar to that for the pass-through regressions, but we modify it in a number of important ways.

First, we need to include all TPO installations in order to capture TPO demand, not just those whose contracts we transcribed. Second, as the CSI applied to the three IOUs but not municipal utilities, we need to treat zip codes with partial IOU-coverage carefully. To that end, we obtained information on all California zip codes serviced by one of the three IOUs as well as zip codes covered 
by California's municipal and other utilities, which were not eligible for the CSI. ${ }^{38}$ We then drop zip codes that are not serviced by one of the three IOUs or serviced in part by an IOU and in part by a municipal utility.

Finally, we applied a few more detailed sample selection rules. We manually went through all zip codes and dropped 13 zip codes that are not flagged as partially outside IOU territory, but a detailed service area map from the California Energy Commission disagrees. ${ }^{39}$ We also drop 133 zip codes with zero population; these are business districts or P.O. boxes.

Third, we aggregate the data to the zip code by year level. When doing so, we are faced with missing variables in the zip code-year combinations where there were no installations. We are also missing demographic data and electrician worker wages data in some cases, as well as TPO prices in zip code-years where there are TPO installations but we do not have contract prices. We interpolate missing data so that we have a balanced panel. We employ the following procedure to fill in zip code by year level prices and control variables. When such variables are missing for a particular observation (most commonly for zip code-year observations with zero installations), we take the county by year average, separately for HO vs. TPO systems. If the county by year aggregate is still missing (highly unlikely, but possible for some variables, such as electricians' wages that are missing for a few sparsely populated counties), we take the population-weighted average over neighboring counties. In the few cases where we are still missing data (all of which are TPO prices in zip code-years where we do not have transcribed contracts in our sample), we use utilityyear averages. In this aggregation process, we sum the installations by year for each zip code and contract type. Since we have a limited time series but only partial coverage of the year 2013, we pro-rate the installation rate for 2013 using the end date for each utility (discussed above) and the fraction of systems that were installed in the sample period over the period $2010-2012$ (44.34\% for SCE, $42.61 \%$ for SDG\&E, and $26.42 \%$ for PG\&E).

Table B.1 provides summary statistics of our demand estimation data from 2010 through 2013. Demand rates for HO and TPO are not statistically different. As was the case for the pass-through data, differences for $\mathrm{HO}$ and TPO system rebates and post-incentive prices are statistically different but relatively modest in terms of economic magnitudes, and no demographic differences stand out besides HO households having just slightly older heads of household and slightly more household ownership.

\section{B.2 Adjusting the CSI Rebates for ITC and MACRS Subsidies}

This section details the method we employed to adjust the CSI rebate to account for its interaction with pre-existing federal incentives, as explained in Section 4.1. Federal incentives available

\footnotetext{
${ }^{38}$ For PG\&E, see https://www.pge.com/tariffs/tm2/pdf/ELEC_MAPS_Service_Area_Map.pdfandwww.pge. com/tariffs/RESZIPS.XLS. For SCE, https://www.sce.com/wps/wcm/connect/690b717f-8c57-469b-a87aad02decbf9d0/MasterZipCode_DiscBulbs.pdf?MOD=AJPERES. For SDG\&E, see https://energydata.sdge.com/. For LADWP, see https://data.lacity.org/A-Livable-and-Sustainable-City/LADWP-Power-use-by-zipcodeGOVSTAT-/a752-uami/data. For other non-IOU zip codes, see https://catalog.data.gov/dataset/u-s-electricutility-companies-and-rates-look-up-by-zipcode-feb-2011-57a7c.

${ }^{39} \mathrm{http}$ ://www.energy.ca.gov/maps/serviceareas/electric_service_areas.html
} 
Table B.1: Descriptive Statistics of Sample for Demand Estimation, 2010-2013.

\begin{tabular}{|c|c|c|c|c|c|}
\hline & \multicolumn{3}{|c|}{ Means } & \multicolumn{2}{|c|}{ Standard Deviations } \\
\hline & $\begin{array}{l}\mathrm{HO} \\
(1)\end{array}$ & $\begin{array}{c}\text { TPO } \\
(2)\end{array}$ & $\begin{array}{c}\text { Difference } \\
(3)\end{array}$ & $\begin{array}{l}\mathrm{HO} \\
(4)\end{array}$ & $\begin{array}{l}\text { TPO } \\
(5)\end{array}$ \\
\hline \multicolumn{6}{|l|}{ Panel A: Installations } \\
\hline Demand rate (installations per 1,000 people) & 0.495 & 0.534 & -0.039 & 2.013 & 2.198 \\
\hline \multicolumn{6}{|l|}{ Panel B. System Characteristics } \\
\hline CSI rebate $(\$ /$ watt $)$ & $\$ 0.42$ & $\$ 0.41$ & $\$ 0.02$ & $\$ 0.35$ & $\$ 0.34$ \\
\hline CSI rebate $(\$)$ & $\$ 2,024$ & $\$ 2,121$ & $-\$ 97^{* *}$ & $\$ 1,689$ & $\$ 1,851$ \\
\hline Post-incentive price (\$/watt) & $\$ 3.89$ & $\$ 3.43$ & $\$ 0.46^{* * *}$ & $\$ 0.89$ & $\$ 0.64$ \\
\hline Post-incentive price $(\$)$ & $\$ 18,432$ & $\$ 18,540$ & $-\$ 108$ & $\$ 4,389$ & $\$ 4,743$ \\
\hline System size (watts) & 5,065 & 5,297 & $-232^{* * *}$ & 1,259 & 1,158 \\
\hline \multicolumn{6}{|l|}{ Panel C. Demographics } \\
\hline Weekly electricians' wages $(\$)$ & $\$ 1,149$ & $\$ 1,149$ & $\$ 0$ & $\$ 210$ & $\$ 210$ \\
\hline Bachelor's degree or higher & $34.6 \%$ & $34.2 \%$ & $0.4 \%$ & $16.6 \%$ & $16.6 \%$ \\
\hline Median age of household head & 40.9 & 40.5 & $0.4^{* * *}$ & 6.1 & 6.0 \\
\hline Percent owners of all households & $52.1 \%$ & $52.0 \%$ & $0.1 \% * *$ & $3.7 \%$ & $3.5 \%$ \\
\hline Median household income $(\$)$ & $\$ 76,681$ & $\$ 76,257$ & $\$ 424$ & $\$ 27,043$ & $\$ 26,779$ \\
\hline Median house value $(\$)$ & $\$ 438,084$ & $\$ 432,417$ & $\$ 5,667$ & $\$ 225,690$ & $\$ 223,624$ \\
\hline Third highest electricity rate tier $(\$ / \mathrm{kWh})$ & $\$ 0.22$ & $\$ 0.22$ & $\$ 0.00$ & $\$ 0.04$ & $\$ 0.04$ \\
\hline Second highest electricity rate tier $(\$ / \mathrm{kWh})$ & $\$ 0.30$ & $\$ 0.30$ & $\$ 0.00$ & $\$ 0.04$ & $\$ 0.04$ \\
\hline Highest electricity rate tier $(\$ / \mathrm{kWh})$ & $\$ 0.31$ & $\$ 0.31$ & $\$ 0.00$ & $\$ 0.05$ & $\$ 0.05$ \\
\hline
\end{tabular}

Notes: Dataset is a balanced panel with 5,384 observations for both HO and TPO at the zip code-year level. Asterisks denote ${ }^{*} p<0.10,{ }^{* *} p<0.05,{ }^{* * *} p<0.01$.

throughout the sample period include the investment tax credit (ITC) for both HO and TPO systems, and the Modified Accelerated Cost Recovery System (MACRS) benefits for TPO systems only. We begin by examining the case of HO systems. Recall that the post-incentive price for HO consumers is the reported total cost minus incentives, such that

$$
p_{H O, i}=T C_{H O, i}-C S I_{H O, i}-I T C_{H O, i},
$$

where $p_{H O, i}$ is the post-incentive price for $\mathrm{HO}$ consumer $i, T C_{H O, i}$ is the total reported pre-incentive cost in the CSI database, $C S I_{H O, i}$ is the total CSI rebate amount awarded, and $I T C_{H O, i}$ is the implied federal ITC benefit. We do not observe the ITC, so we calculate this assuming that it is fully monetized for all cases. For HO consumers, the CSI rebate is considered a price reduction for tax credit purposes. Thus, the $30 \%$ tax credit applies to the after-rebate net price paid by the customer:

$$
I T C_{H O, i}=0.3 *\left(T C_{H O, i}-C S I_{H O, i}\right) .
$$

The pass-through of the ITC and CSI incentives cannot be separately identified in our regression model because they are linear functions of each other, however we must account for the way in which 
they interact. As implied by Equation B.2, a one-dollar increase in the CSI rebate is effectively a 70 cent increase in total subsidies because the CSI mechanically decreases the value of the ITC by 30 cents. We account for this interaction by adjusting the CSI rebate amount that is used in our pass-through regressions. To do that, note that we can re-write Equation B.1 such that

$$
p_{H O, i}=0.7 *\left(T C_{H O, i}-C S I_{H O, i}\right) .
$$

However, if we did not adjust our measure of the CSI subsidy, our regression would estimate

$$
p_{i} \sim \alpha+\beta C S I_{i}+\varepsilon_{i},
$$

where a one-dollar increase in the CSI subsidy would be interpreted as a one-dollar increase in the total subsidy received. As the actual one-dollar increase in the CSI is worth only 70 cents from the consumer's and installer's perspectives, we multiply the CSI subsidies by a correction factor of 0.7 , as we want to interpret our pass-through coefficient $\beta$ as the impact on prices of a full one-dollar subsidy increase.

Adjusting for federal incentives for TPO systems differs somewhat from the HO adjustment for two reasons: the ITC is calculated in a slightly different way, and TPO systems also benefit from MACRS. The post-incentive price that we construct for TPO systems is a net present cost calculation that embeds all incentives (since contract terms are subsidy-inclusive). As such, we do not need to explicitly net out the ITC and MACRS from a gross cost measure (as we do for HO consumers). However, we note that for TPO consumers

$$
p_{T P O, i} \equiv N P C_{T P O, i}=U_{i}+\sum_{y=1}^{t} \frac{\text { payment }_{i y}}{(1+d)^{t}},
$$

where $p_{T P O, i}$ is the post-incentive price of system $i$, or the net present cost of the contract to the customer as described by Equation 7, which embeds the ITC and MACRS. As before, we need to account for these other incentives in our pass-through regressions as they interact with the CSI rebate. First consider the ITC for TPO consumers. The CSI rebate is not a price reduction for tax credit purposes as it is for HO consumers. Instead, the federal ITC received by third parties is based on gross installed cost: $I T C_{T P O, i}=0.3 * T C_{T P O, i}$. The ITC is thus unaffected by the CSI as the basis for the $30 \%$ credit is not reduced by the CSI rebate amount. However, the IRS considers the CSI rebate to be earned income and therefore subject to corporate taxes. Hence, the effective CSI subsidy is $\left(1-t_{c}\right) C S I$, where $t_{c}$ is the corporate tax rate. Hence, we need to multiply the CSI subsidies by $\left(1-t_{c}\right)$ in the TPO case in order to interpret our pass-through coefficient as the impact of a full dollar increase in the rebate. We do not observe the effective marginal tax rate of each installer in our sample, but following Borenstein (2017), we assume it is 30\% - close 
but somewhat lower than the $35 \%$ rate for large companies. Using $35 \%$ would scale up our ITC pass-through estimates and make the estimated difference between HO and TPO pass-through even more pronounced.

The second federal subsidy to take into account is MACRS. Over our entire sample period, residential solar PV systems were eligible for 5-year accelerated depreciation as well as an especially high "bonus" depreciation in the first year. For systems placed into service after September 8, 2010 and before January 1, 2012, the first-year bonus depreciation rate was 100\%; it was $50 \%$ during the other periods in our sample. Under $50 \%$ first-year bonus depreciation, the depreciation schedule was $(50 \%$ bonus $+10 \%$ MACRS $=) 60 \%, 16 \%, 9.6 \%, 5.76 \%, 5.76 \%$ and $2.88 \%$ for years one through six, respectively. Under $100 \%$ first-year bonus depreciation, the system was fully depreciated for tax purposes in year one.

Our goal is to calculate a MACRS "adjustment factor" based upon the structure of the MACRS program assuming a one-dollar increase in the CSI rebate. We use Borenstein (2017)'s assumptions. Again, we want to interpret a one-dollar increase in the CSI subsidy as a one-dollar increase in total subsidy received. The reasoning is similar to that for the ITC adjustment in the case of HO: there is a reduction in the present value of the MACRS benefit following a one-dollar increase in CSI because firms were able to depreciate $85 \%$ of the system cost after state rebates. In other words, the allowable depreciable basis is equal to $0.85 *(T C-C S I)$. The net present value of the reduction in tax savings (depreciation benefits) resulting from a one-dollar increase in the CSI for TPO systems is

$$
f_{M A C R S}=\sum_{y=1}^{6}\left(\frac{m_{y}}{(1+r)^{y}} * t_{c} * D\right)
$$

where $m_{y}$ is the MACRS recovery rate in year $y, r$ is the firm's discount rate, and $t_{c}$ is the firm's marginal corporate tax rate (which we assume to be $30 \%$, following Borenstein (2017)). $D$ is the allowable depreciable basis, which is equal to 0.85 for solar PV systems.

We calculate real adjustment factors for a range of nominal discount rate assumptions that align with our NPC calculations (2\% to 12\%). Furthermore, we calculate different sets of adjustment factors based on when the program allowed for $50 \%$ and $100 \%$ bonus depreciation. We assume that all third parties took advantage of the MACRS program. We thus determine if systems qualified for $50 \%$ or $100 \%$ bonus deprecation based upon installation date, since eligibility was determined based on the date the system went into service. This date is not included in the CSI database, so we matched the CSI data to the publicly available NEM interconnection dataset. $f_{M A C R S}$ ranges from 0.21 to 0.25 depending on the discount rate and the type of bonus depreciation.

Finally, we adjust the CSI rebates for ITC, corporate taxes, and MACRS benefits for our pass-through regressions such that 


$$
\text { AdjustedCSI } I_{H O, i}=0.7 * C S I_{H O, i}
$$

and

$$
\text { AdjustedCSI } I_{T P O, i}=0.7 * C S I_{T P O, i} *\left(1-f_{M A C R S}\right) .
$$

\section{Additional Figures and Tables}

\section{C.1 Additional Theory Figures}

In Figure 1 of the main text we show how over-shifting occurs in the presence of market power when demand is log-convex. Figure C.1 demonstrates two related cases where pass-through cannot exceed unity to further illustrate why both sufficiently convex demand and market power are needed to explain over-shifting. Panel A illustrates how pass-through falls between 0 and $100 \%$ under perfect competition but with convex demand. Perfectly vertical marginal costs would imply $0 \%$ passthrough and flat marginal costs would imply $100 \%$ pass-through. Panel B shows how pass-through is exactly $50 \%$ for the case of monopoly but with linear demand and constant marginal costs.

Figure C.1: Two Examples of Pass-Through Without Over-Shifting

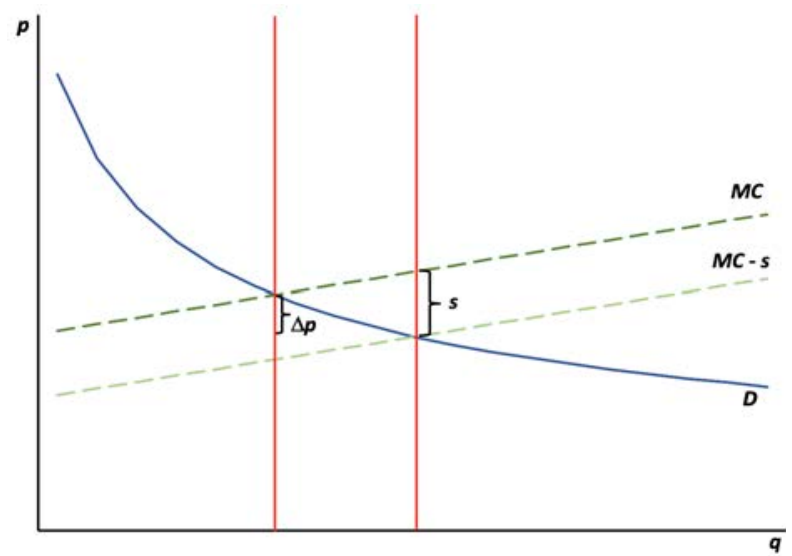

(a) Pass-Through under Perfect Competition and Constant Elasticity Demand

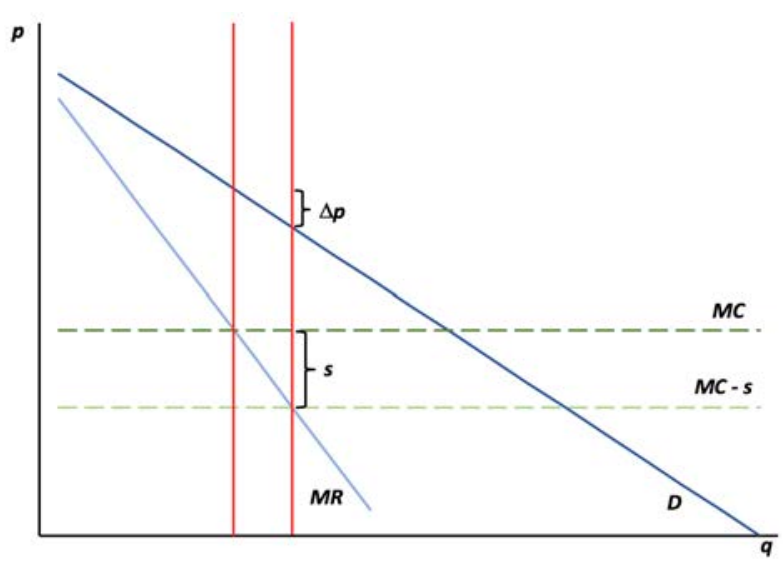

(b) Pass-Through for a Monopolist with Linear Demand and Constant Marginal Costs

Note: Figure shows the price effect of a subsidy $s$ on the price $p$ under perfect competition when there is constant elasticity demand and when $p$ is set by a monopolist under linear demand. $M C$ refers to marginal cost, $D$ to demand, and $M R$ to marginal revenue. The constant elasticity parameter in panel $\mathrm{A}$ is $\epsilon=-0.5$. 


\section{C.2 Additional Figures and Tables for the Pass-Through Estimates}

Figure C.2 shows the total daily installations in each of the three IOU territories for our sample period 2010Q1-2013Q2. ${ }^{40}$ The figures demonstrate some amount of bunching of applications just before the rebate drop dates. This is consistent with the findings in Hughes and Podolefsky (2015). ${ }^{41}$

This bunching reflects a certain degree of strategic timing behavior on part of consumers and installers. These drop dates could not be perfectly foreseen as they were triggered by reaching a threshold of cumulative installed capacity within each IOU. This date is hard to predict exactly, however the CSI announced on a public website how many CSI megawatts (MW) worth of rebates remained in the current incentive step level. This web-based CSI Trigger Tracker allowed users to anticipate when the rebates were going to drop to the next level by comparing "MW Under Review" with "MW Remaining". The rebate level is determined at the time of the reservation, not the time of project completion, so it was possible to strategically submit reservations as each IOU approached step capacity targets.

Table C.1 shows our baseline specification with increasingly flexible controls and fixed effects. Columns 1-7 gradually add more controls. Throughout all specifications, we find that the difference in pass-through between TPO and HO consumers is large and statistically significant, but we need detailed controls to estimate pass-through more accurately, especially for HO consumers.

\section{C.3 Additional Demand Estimation Results}

\section{C.3.1 First Stage}

Table C.2 reports the first stage regressions for the solar panel price and its square, along with the Sanderson-Windmeijer multivariate F-test for excluded instruments.

\section{C.3.2 Robustness Checks}

Table C.3 shows how the demand parameters vary with two important alternative sample selection or variable construction rules. First, we compute the solar installation rate by dividing installations by the number of people who live in houses they own (using information on owner-occupied housing from the census) instead of total population. Renters are unlikely to install solar systems as they do not always capture the full benefits because of limited housing tenure, their apartments or houses are typically less suitable for solar panels, and they need to get property owner approval. Relatedly, homeowners who lease their properties to others may be unlikely to install solar panels when they

\footnotetext{
${ }^{40}$ Note that daily "installations" are actually "rebate reservations", since the dates refer to the day when rebate reservations were filed as opposed to when installations were completed.

${ }^{41}$ CSI residential rebates in the SDG\&E region were briefly suspended after January $31^{\text {st }}, 2013$, but it became clear soon afterwards that residential rebates would continue at the same rate per watt as $\$ 5$ million from the commercial solar project budget was shifted to residential installations (Center for Sustainable Energy 2014). Around January $31^{\text {st }}$, however, some consumers may have thought the CSI rebates had run out while in fact they had not. We therefore show this date as a dotted vertical line in Figure C.2, panel B.
} 
Figure C.2: Total Installations per Day for (a) SCE, (b) SDG\&E and (c) PG\&E.

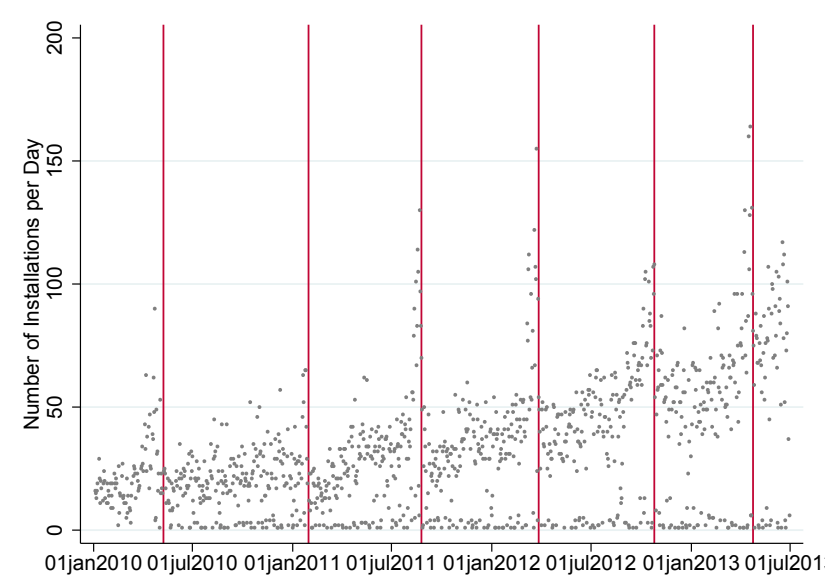

(a) Southern California Edison

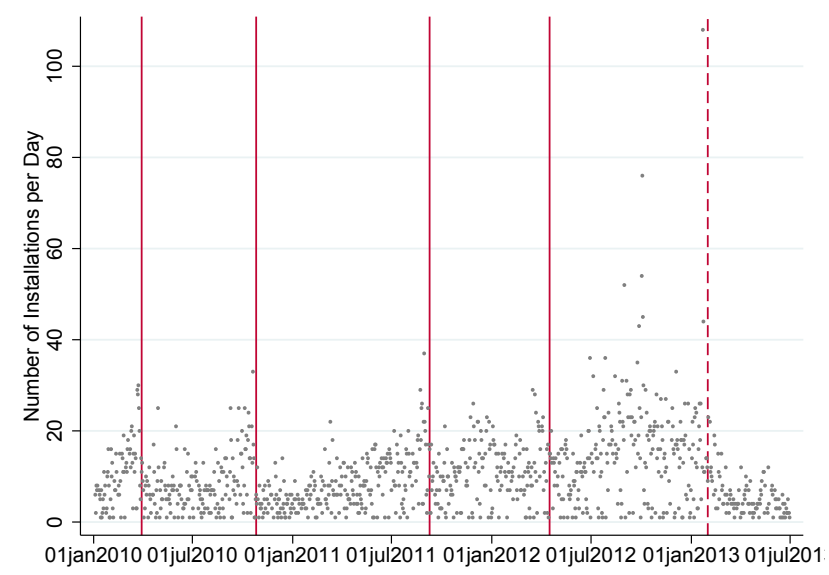

(b) San Diego Gas and Electric

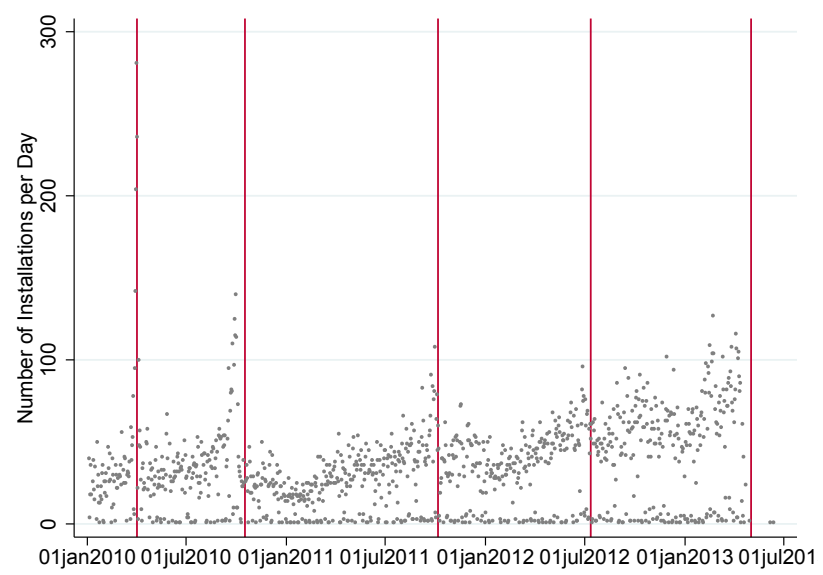

(c) Pacific Gas and Electric

Note: The dotted vertical line for SDG\&E on January $31^{\text {st }}, 2013$ indicates a temporary rebate suspension but not an actual rebate drop. 
Table C.1: Baseline Estimates with Increasingly Flexible Controls

\begin{tabular}{|c|c|c|c|c|c|c|c|c|c|c|}
\hline & \multicolumn{2}{|c|}{$(1)$} & \multicolumn{2}{|c|}{$(2)$} & \multicolumn{2}{|c|}{$(3)$} & \multicolumn{2}{|c|}{$(4)$} & \multicolumn{2}{|c|}{$(5)$} \\
\hline $\begin{array}{l}\text { Panel A. Pooled } \\
\text { Incentive }\end{array}$ & \multicolumn{2}{|c|}{$\begin{array}{l}-0.044 \\
(0.119)\end{array}$} & \multicolumn{2}{|c|}{$\begin{array}{c}-0.286^{* * *} \\
(0.103)\end{array}$} & \multicolumn{2}{|c|}{$\begin{array}{c}-0.546^{* * *} \\
(0.091)\end{array}$} & \multicolumn{2}{|c|}{$\begin{array}{c}-0.555^{* * *} \\
(0.087)\end{array}$} & \multicolumn{2}{|c|}{$\begin{array}{c}-0.778^{* * *} \\
(0.063)\end{array}$} \\
\hline $\begin{array}{l}\text { Incentive } \\
* 1[\text { system }=\mathrm{TPO}]\end{array}$ & \multicolumn{2}{|c|}{$\begin{array}{c}-1.435^{* * *} \\
(0.259)\end{array}$} & \multicolumn{2}{|c|}{$\begin{array}{c}-1.383^{* * *} \\
(0.267)\end{array}$} & \multicolumn{2}{|c|}{$\begin{array}{c}-1.281^{* * *} \\
(0.262)\end{array}$} & \multicolumn{2}{|c|}{$\begin{array}{c}-1.429^{* * *} \\
(0.261)\end{array}$} & \multicolumn{2}{|c|}{$\begin{array}{c}-0.750^{* * *} \\
(0.234)\end{array}$} \\
\hline $1[$ system $=$ TPO $]$ & \multicolumn{2}{|c|}{$\begin{array}{c}-0.558^{* * *} \\
(0.216)\end{array}$} & \multicolumn{2}{|c|}{$\begin{array}{l}-0.022 \\
(0.217)\end{array}$} & \multicolumn{2}{|c|}{$\begin{array}{l}-0.198 \\
(0.229)\end{array}$} & \multicolumn{2}{|c|}{$\begin{array}{l}-0.196 \\
(0.222)\end{array}$} & \multicolumn{2}{|c|}{$\begin{array}{l}-0.378^{*} \\
(0.203)\end{array}$} \\
\hline $\begin{array}{l}\text { Number of obs. } \\
\text { p-value: HO pass-through }>-1 \\
\text { p-value: TPO pass-through }<-1\end{array}$ & \multicolumn{2}{|c|}{$\begin{array}{c}28,108 \\
0.000 \\
0.024\end{array}$} & \multicolumn{2}{|c|}{$\begin{array}{c}28,108 \\
0.000 \\
0.005\end{array}$} & \multicolumn{2}{|c|}{$\begin{array}{c}28,108 \\
0.000 \\
0.001\end{array}$} & \multicolumn{2}{|c|}{$\begin{array}{c}28,108 \\
0.000 \\
0.000\end{array}$} & \multicolumn{2}{|c|}{$\begin{array}{c}28,108 \\
0.000 \\
0.013\end{array}$} \\
\hline Panel B. Separated & $\mathrm{HO}$ & TPO & $\mathrm{HO}$ & TPO & $\mathrm{HO}$ & TPO & $\mathrm{HO}$ & TPO & $\mathrm{HO}$ & TPO \\
\hline Incentive & $\begin{array}{l}-0.067 \\
(0.120)\end{array}$ & $\begin{array}{c}-0.923^{* * *} \\
(0.294)\end{array}$ & $\begin{array}{c}-0.309^{* * *} \\
(0.103)\end{array}$ & $\begin{array}{c}-1.070^{* * *} \\
(0.282)\end{array}$ & $\begin{array}{c}-0.567^{* * *} \\
(0.092)\end{array}$ & $\begin{array}{c}-1.186^{* * *} \\
(0.338)\end{array}$ & $\begin{array}{c}-0.578^{* * *} \\
(0.088)\end{array}$ & $\begin{array}{c}-1.202^{* * *} \\
(0.351)\end{array}$ & $\begin{array}{c}-0.787^{* * *} * \\
(0.063)\end{array}$ & $\begin{array}{c}-1.333^{* * *} \\
(0.351)\end{array}$ \\
\hline $\begin{array}{l}\text { Number of obs. } \\
\text { p-value: HO pass-through }>-1 \\
\text { p-value: TPO pass-through }<-1\end{array}$ & $\begin{array}{c}27,015 \\
0.000\end{array}$ & $\begin{array}{l}1,093 \\
0.603\end{array}$ & $\begin{array}{c}27,015 \\
0.000\end{array}$ & $\begin{array}{l}1,093 \\
0.402\end{array}$ & $\begin{array}{c}27,015 \\
0.000\end{array}$ & $\begin{array}{l}1,093 \\
0.291\end{array}$ & $\begin{array}{c}27,015 \\
0.000\end{array}$ & $\begin{array}{l}1,093 \\
0.282\end{array}$ & $\begin{array}{c}27,015 \\
0.000\end{array}$ & $\begin{array}{l}1,093 \\
0.172\end{array}$ \\
\hline Controls & $\mathrm{x}$ & $\mathrm{x}$ & $\mathrm{x}$ & $\mathrm{x}$ & $\mathrm{x}$ & $\mathrm{x}$ & $\mathrm{x}$ & $\mathrm{x}$ & $\mathrm{x}$ & $\mathrm{x}$ \\
\hline Utility FE & $\mathrm{x}$ & $\mathrm{x}$ & $\mathrm{x}$ & $\mathrm{x}$ & $\mathrm{x}$ & $\mathrm{x}$ & $\mathrm{x}$ & $\mathrm{x}$ & $\mathrm{x}$ & $\mathrm{x}$ \\
\hline Manufacturer FE & & & $\mathrm{x}$ & $\mathrm{x}$ & $\mathrm{x}$ & $\mathrm{x}$ & $\mathrm{x}$ & $\mathrm{x}$ & $\mathrm{x}$ & $\mathrm{x}$ \\
\hline Module FE & & & & & $\mathrm{x}$ & $\mathrm{x}$ & $\mathrm{x}$ & $x$ & $\mathrm{x}$ & $\mathrm{x}$ \\
\hline $\begin{array}{l}\text { County FE } \\
\text { Installer FE }\end{array}$ & & & & & & & $\mathrm{x}$ & $\mathrm{x}$ & $\begin{array}{l}\mathrm{x} \\
\mathrm{x}\end{array}$ & $\begin{array}{l}\mathrm{x} \\
\mathrm{x}\end{array}$ \\
\hline $\begin{array}{l}\text { Quadratic contract } \\
\text { type time trends }\end{array}$ & $\mathrm{x}$ & $\mathrm{x}$ & $\mathrm{x}$ & $\mathrm{x}$ & $\mathrm{x}$ & $\mathrm{x}$ & $\mathrm{x}$ & $\mathrm{x}$ & $\mathrm{x}$ & $\mathrm{x}$ \\
\hline
\end{tabular}

Notes: Dependent variable is the post-incentive system price per watt. Data cover systems installed in California for consumers who applied for the CSI rebate during the period 2010-Q2 2013. Controls include census tract level demographics and a dummy if there is more than one inverter. A $7 \%$ discount rate is assumed for the net present cost and MACRS calculations. Standard errors clustered by zip code. In Panel A, the p-value labeled "HO pass-through $>-1$ " is the one-sided p-value of $H_{0}: \beta_{1} \leq-1$ vs. $H_{a}: \beta_{1}>-1$. p-value labeled "TPO pass-through $<-1$ " is the one-sided p-value of $H_{0}: \beta_{1}+\beta_{2} \geq-1$ vs. $H_{a}: \beta_{1}+\beta_{2}<-1$. In panel $\mathrm{B}$, all tests are performed on the single coefficient on the incentive variable. Asterisks denote ${ }^{*} p<0.10,{ }^{* *} p<0.05$, ${ }^{* * *} p<0.01$ for $H_{0}: \beta=0$ vs. $H_{a}: \beta \neq 0$. 
Table C.2: First-Stage Regressions for HO vs. TPO Systems

\begin{tabular}{|c|c|c|c|c|}
\hline & (1) & $\overline{(2)}$ & (3) & (4) \\
\hline & \multicolumn{2}{|c|}{ First-Stage Regression of Price } & \multicolumn{2}{|c|}{ First-Stage Regression of Price ${ }^{2}$} \\
\hline & $\mathrm{HO}$ & TPO & $\mathrm{HO}$ & $\mathrm{TPO}$ \\
\hline Incentive & $\begin{array}{c}2.026^{* * *} \\
(0.394)\end{array}$ & $\begin{array}{c}-2.779^{* * *} \\
(0.317)\end{array}$ & $\begin{array}{c}19.644^{* * *} \\
(4.001)\end{array}$ & $\begin{array}{c}-21.603^{* * *} \\
(2.498)\end{array}$ \\
\hline Incentive $^{2}$ & $\begin{array}{c}-1.688^{* * *} \\
(0.384)\end{array}$ & $\begin{array}{c}1.973^{* * *} \\
(0.334)\end{array}$ & $\begin{array}{c}-14.875^{* * *} \\
(3.961)\end{array}$ & $\begin{array}{c}15.769^{* * *} \\
(2.600)\end{array}$ \\
\hline Electricians' wages & $\begin{array}{l}0.001 * * \\
(0.0005)\end{array}$ & $\begin{array}{c}-0.004^{* * *} \\
(0.0004)\end{array}$ & $\begin{array}{c}0.011^{* * *} \\
(0.004)\end{array}$ & $\begin{array}{c}-0.021^{* * *} \\
(0.004)\end{array}$ \\
\hline Electricians' wages ${ }^{2}$ & $\begin{array}{l}-2.39 * 10^{-7} \\
\left(2.10 * 10^{-7}\right)\end{array}$ & $\begin{array}{c}1.60 * 10^{-6 * * *} \\
\left(1.90 * 10^{-7}\right)\end{array}$ & $\begin{array}{c}-3.51 * 10^{-6 *} \\
\left(1.85 * 10^{-6}\right)\end{array}$ & $\begin{array}{c}9.08 * 10^{-6 * * *} \\
\left(1.55 * 10^{-6}\right)\end{array}$ \\
\hline First stage F-statistic & 10.40 & 18.86 & 10.16 & 18.35 \\
\hline p-value & 0.000 & 0.000 & 0.000 & 0.000 \\
\hline Controls & $x$ & $x$ & $\mathrm{x}$ & $\mathrm{x}$ \\
\hline County FE & $\mathrm{x}$ & $\mathrm{x}$ & $\mathrm{x}$ & $\mathrm{x}$ \\
\hline Year FE & $\mathrm{x}$ & $\mathrm{x}$ & $\mathrm{x}$ & $\mathrm{x}$ \\
\hline Number of observations & 5,196 & 5,196 & 5,196 & 5,196 \\
\hline
\end{tabular}

Notes: Observations are at the zip code by year level. Data cover systems installed in California for consumers who applied for the CSI rebate during the period 2010-Q2 2013. Controls includes the same demographics that we use in Table 2, as well as tiered electricity rates. A $7 \%$ discount rate is assumed for the net present cost and MACRS calculations. F-statistic is the Sanderson-Windmeijer multivariate F-test of excluded instruments. Standard errors clustered by zip code. Asterisks denote ${ }^{*} p<0.10,{ }^{* *} p<0.05,{ }^{* * *} p<0.01$. 
do not expect to benefit from the electricity bill savings through higher rents. Second, we estimate demand using all zip codes, including those with populations below 100 people.

Table C.3: Robustness of Demand Estimates

\begin{tabular}{|c|c|c|c|c|}
\hline & (1) & (2) & $(3)$ & (4) \\
\hline & \multicolumn{2}{|c|}{ OLS } & \multicolumn{2}{|c|}{ IV } \\
\hline & $\mathrm{HO}$ & TPO & $\mathrm{HO}$ & TPO \\
\hline Price & $\begin{array}{c}-0.485^{* * *} \\
(0.155)\end{array}$ & $\begin{array}{c}-0.362^{* *} \\
(0.174)\end{array}$ & $\begin{array}{c}-0.936 \\
(1.718)\end{array}$ & $\begin{array}{l}-2.996 \\
(4.000)\end{array}$ \\
\hline Price $^{2}$ & $\begin{array}{c}0.048^{* * *} \\
(0.015)\end{array}$ & $\begin{array}{c}0.053^{* *} \\
(0.022)\end{array}$ & $\begin{array}{c}0.089 \\
(0.191)\end{array}$ & $\begin{array}{c}0.429 \\
(0.514)\end{array}$ \\
\hline $\begin{array}{l}\text { Mean of dependent variable } \\
\text { First stage F-statistic (price) } \\
\left.\text { First stage F-statistic (price }{ }^{2}\right) \\
\text { Number of observations }\end{array}$ & 0.870 & 0.976 & $\begin{array}{c}0.870 \\
10.40^{* * *} \\
10.16^{* * *} \\
5,196\end{array}$ & $\begin{array}{c}0.976 \\
18.86^{* * *} \\
18.35^{* * *} \\
5,196\end{array}$ \\
\hline
\end{tabular}

Panel B. Including Zip Codes with Less Than 100 Inhabitants

\begin{tabular}{|c|c|c|c|c|}
\hline & \multicolumn{2}{|c|}{ OLS } & \multicolumn{2}{|c|}{ IV } \\
\hline & $\mathrm{HO}$ & TPO & $\mathrm{HO}$ & TPO \\
\hline Price & $\begin{array}{l}-0.489 \\
(0.311)\end{array}$ & $\begin{array}{c}-0.258^{*} \\
(0.140)\end{array}$ & $\begin{array}{l}-1.754 \\
(1.873)\end{array}$ & $\begin{array}{l}-3.166 \\
(2.420)\end{array}$ \\
\hline Price $^{2}$ & $\begin{array}{c}0.048^{*} \\
(0.028)\end{array}$ & $\begin{array}{c}0.039^{* *} \\
(0.018)\end{array}$ & $\begin{array}{c}0.208 \\
(0.235)\end{array}$ & $\begin{array}{c}0.460 \\
(0.321)\end{array}$ \\
\hline $\begin{array}{l}\text { Mean of dependent variable } \\
\text { First stage F-statistic (price) } \\
\text { First stage F-statistic (price }{ }^{2} \text { ) } \\
\text { Number of observations }\end{array}$ & 0.495 & 0.534 & $\begin{array}{c}0.495 \\
11.03^{* * *} \\
10.75^{* * *} \\
5,384\end{array}$ & $\begin{array}{c}0.534 \\
21.48^{* * *} \\
20.91^{* * *} \\
5,384\end{array}$ \\
\hline
\end{tabular}

Notes: Dependent variable is the solar system installation rate, either based on owner-population (panel A) or based on total population (panels B and C). Observations are at the zip code by year level. Data cover systems installed in California for consumers who applied for the CSI rebate during the period 2010-Q2 2013. Controls includes the same demographics that we use in Table 2, as well as tiered electricity rates. A $7 \%$ discount rate is assumed for the net present cost and MACRS calculations. IV estimates in columns 3 and 4 instrument for (squared) price using the (squared) CSI rebate and the (squared) county-level electrician/wiring wage rate. F-statistic is the SandersonWindmeijer multivariate F-test of excluded instruments (for each of the first-stage regressions). Standard errors clustered by zip code. Asterisks denote ${ }^{*} p<0.10,{ }^{* *} p<0.05,{ }^{* * *} p<0.01$.

We conclude that the results when adjusting for homeownership are similar to those in the main specification in Table 6. The parameter values are larger in absolute value, but note that the mean of the dependent variable (the installation rate) is about twice as large since we divide by owner-occupied housing population, not total population. The implied elasticities are also similar. Similarly, dropping small zip codes does not qualitatively affect our results: the estimates are smaller but still indicate substantial convexity. Similarly, including small zip codes does not qualitatively affect our results: the estimates still indicate substantial convexity.

We also ran IV specifications using only the linear CSI rebate and electrician/wiring wage rate 
(but not their squares) as instruments. In this case, we have a weak instruments problem for the TPO regression. The coefficient on the squared price indicates convexity, but the TPO point estimates are large and noisy yet still not statistically different from any of the point estimates from alternative specifications. ${ }^{42}$

\section{C.3.3 Calculating Convexity Measures}

In order to calculate the convexity parameter $\varepsilon_{m s}$ of Equation 2, we need inverse demand and therefore we invert our estimated demand equation. This is straightforward using the quadratic formula and price and squared price parameters estimated in Table 6. We first calibrate the constant by evaluating our estimated demand equations (one for HO and one for TPO) at a fixed price and with all other control variables at their sample means. From this, we obtain a simplified demand expression $q=a p^{2}+b p+c$ (with $a$ and $b$ as the estimates from Table 6 and $c$ calibrated as described above). Next, we solve for $p(q)$ using the quadratic formula. We differentiate the resulting expression to obtain $p^{\prime}(q)$ and $p^{\prime \prime}(q)$. This allows us to evaluate the criterion given by Equation A.8 along different points at the demand curves, where $1 / \varepsilon_{m s}<0$ indicates over-shifting under the assumptions of the model. The results are discussed in Section 6 of the main paper.

\section{Additional References}

Center for Sustainable Energy. 2014. "CSI Rebates Winding Down for San Diego Homeowners."

Hois, E. 2016. "Selecting the Size of Your Solar PV System." SolarReviews.

\footnotetext{
${ }^{42}$ For HO, the coefficients on price and squared price equal -0.812 and 0.062 , respectively. For TPO, these coefficients are -48.304 and 6.443. None of these coefficients are statistically significant. For TPO, the p-value of the SandersonWindmeijer F-statistics for price and squared price are 0.22 and 0.22 , respectively.
} 